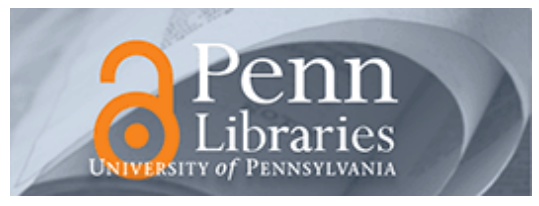

University of Pennsylvania

ScholarlyCommons

Marketing Papers

Wharton Faculty Research

2016

\title{
Conspicuous Consumption on the Long Tail: How can Luxury Brands Benefit from Counterfeits?
}

Pinar Yildirim

University of Pennsylvania

Zhenqi Liu

University of Pennsylvania

Z. John Zhang

University of Pennsylvania

Follow this and additional works at: https://repository.upenn.edu/marketing_papers

Part of the Advertising and Promotion Management Commons, Business Administration, Management, and Operations Commons, Business Analytics Commons, Fashion Business Commons, Marketing Commons, and the Sales and Merchandising Commons

Recommended Citation

Yildirim, P., Liu, Z., \& Zhang, Z. (2016). Conspicuous Consumption on the Long Tail: How can Luxury Brands Benefit from Counterfeits?. http://dx.doi.org/10.2139/ssrn.2848511

This paper is posted at ScholarlyCommons. https://repository.upenn.edu/marketing_papers/390

For more information, please contact repository@pobox.upenn.edu. 


\title{
Conspicuous Consumption on the Long Tail: How can Luxury Brands Benefit from Counterfeits?
}

\begin{abstract}
We study how luxury brands can use product line expansion as a strategy when facing a threat from the counterfeit market. Consumers who are status-conscious consider the benefits and costs of buying luxury items in order to strengthen the beliefs of others about their status. Our findings suggest that product line expansion strategy serves these high-end consumers and their motives to strengthen their status image. In a market with counterfeiters, consumers have an incentive to buy additional products in order to reduce the uncertainty of their status signals. Increasing consumption makes it harder for others to imitate status when authentic brands signal quality and status with higher precision compared to counterfeits. Since each luxury item purchased contributes to one's status in a marginally declining fashion, it is rational for a luxury brand to expand its product line such that it maintains its core product and introduces peripheral products with lower status signalling benefits and prices. We further show that an increasing counterfeit market share can increase status-conscious consumers' willingness to pay for luxury goods. As a result, presence of counterfeiters can increase the profit of a luxury brand.
\end{abstract}

\section{Keywords}

luxury brands, conspicuous consumption, status signalling, product line expansion

\section{Disciplines}

Advertising and Promotion Management | Business | Business Administration, Management, and Operations | Business Analytics | Fashion Business | Marketing | Sales and Merchandising 


\title{
Conspicuous Consumption on the Long Tail: How can luxury brands benefit from counterfeits?
}

\author{
Pinar Yildirim, Zhenqi Liu, Z. John Zhang*
}

\begin{abstract}
We study how luxury brands can use product line expansion as a strategy when facing a threat from the counterfeit market. Consumers who are status-conscious consider the benefits and costs of buying luxury items in order to strengthen the beliefs of others about their status. Our findings suggest that product line expansion strategy serves these high-end consumers and their motives to strengthen their status image. In a market with counterfeiters, consumers have an incentive to buy additional products in order to reduce the uncertainty of their status signals. Increasing consumption makes it harder for others to imitate status when authentic brands signal quality and status with higher precision compared to counterfeits. Since each luxury item purchased contributes to one's status in a marginally declining fashion, it is rational for a luxury brand to expand its product line such that it maintains its core product and introduces peripheral products with lower status signalling benefits and prices. We further show that an increasing counterfeit market share can increase status-conscious consumers' willingness to pay for luxury goods. As a result, presence of counterfeiters can increase the profit of a luxury brand.
\end{abstract}

Keywords: Luxury brands, conspicuous consumption, status signalling, product line expansion

${ }^{*}$ Yildirim is an Assistant Professor of Marketing (pyild@wharton.upenn.edu). Address: 748 Huntsman Hall, 3730 Walnut St. The Wharton School, University of Pennsylvania, Philadelphia PA, 19104. Liu is a doctoral candidate in Department of Economics of the University of Pennsylvania. Zhang is Murrel J. Ades Professor Professor of Marketing at the Wharton School of the University of Pennsylvania. All correspondence can be directed to the first author. We thank Eric Bradlow, Kinshuk Jerath, Uppender Subramanian, and Yi Zhu for their comments on the manuscript. 


\section{Motivation}

Despite recent economic crises, the global demand for luxury products increased over the past decades (D'Arpizio et al., 2015). The growth of luxury brands was accompanied by an even greater level of counterfeit activity, elevating concerns among managers and policy makers about the potential harm to brands and consumers. A counterfeit is a lower quality, lower price imitation of an authentic product, often manufactured upon infringing a copyright. Luxury brand managers are concerned that illegal reproductions of their products cheapen the image of their brand, steal demand from their goods, reduce profits, and ultimately reduce their investment into creation of new products. Governments and law enforcement offices pursue a global fight to combat counterfeit activity based on the assumption that these listed claims hold. But do high levels of counterfeit activity necessarily hurt luxury brands? Is it possible that these brands could benefit from the market for counterfeits?

In this paper, we study a luxury brand facing a threat from the counterfeit market. We focus on one particular strategic choice of the brand: product line extension by adding low status, low priced goods to the portfolio. Competing with a sophisticated counterfeiter, a luxury brand can follow a number of strategies to maximize its profits. We focus on the effect of expanding the product line, which allows consumers to increase their consumption and strengthen their status signals. Formally, our study addresses the following questions: How does the desire of status signalling influence the choice of goods and preference for variety in luxury consumption? Facing a threat from counterfeits, can luxury brands use product line expansion as a strategy to extract more rent? What is the rationale behind a luxury brand's product line expansion? Can a threat from counterfeiters benefit luxury brands?

Consumers' desire to signal status is a characteristic generally attributed to the consumption of luxury brands. Status, one's position in a social hierarchy (Webster Jr. and Wind, 1972), is considered to be an indication of her desirable qualities such as wealth, knowledge, and taste, attractive to individuals in matters of social, cultural, and economic exchanges. Generally, a higher status is believed to provide individuals with greater opportunities (Flynn, 2003; Besley and Ghatak, 2008; Sauder et al., 2012; Bhattacharya and Dugar, 2014). In instances of connecting with others for friendship or romance, in seeking employment or admittance into college, signals of status can improve one's outcome expectations. An extensive literature studies what contributes to one's status perception, summarizing factors such as personality traits and physical attractiveness (Anderson et al., 2001), culture (Torelli et al., 2014), financial well-being (Campbell and Henretta, 1980), and social connections (Lin, 1999). Among these, perhaps the most relevant to marketers are individuals' revealed product and brand consumption choices. Consumers commonly signal status 
via possession of status goods such as jewelry, fashion goods, or cars (Leibenstein, 1950; Bagwell et al., 1996). Ownership of status goods signal wealth, taste, knowledge of quality, and the ability to access high-priced and scarce items. ${ }^{1}$ The need to attain status breeds the demand for luxury brands. We build a model considering these unique properties of status goods. We assume that, unlike ordinary goods, status goods emit signals about the qualities and identity of a consumer, and each signal can be interpreted in combination with other signals to build one's overall status or image. Consumption of each luxury item signals the status of an individual at varying degrees of uncertainty. In this environment, we model how others' beliefs about one's status are formed. Specifically, we model how consumers, upon observing signals from consumed items, update their perception about the consuming person's status in a Bayesian fashion. We therefore construct the utility of a status-conscious consumer assuming that status is a perception in the eyes of others. ${ }^{2}$

The consumers who are status-conscious consider the benefits and costs of buying luxury items in order to strengthen the beliefs of others about their status. They have private information about the authenticity of the goods they consume. Consumers who desire to signal their status will find it worthwhile to buy a multitude of products or have higher willingness to pay to make their status signals more credible by a costly commitment to differentiate themselves from others. Consistent with these desires, it is rational for a luxury brand to make the choice of strategic product line expansion. Anecdotal observations also support the notion that luxury brands are moving towards expanding their product portfolios to include items which are considered less powerful signals of status and are offered at lower prices. Louis Vuitton offers handbags, but also cell phone covers and key holders. McLaren manufactures luxury cars, but also sells baseball caps. On the surface, the movement of offering lower-priced, lower status goods may give the impression that these luxury brands are trying to reach new, lower income consumer segments. This, however, may not be the only reason according to our analysis. Our framework suggests that product line expansion also serves the high-end, status-conscious consumers and their motives to strengthen their status image. As other consumers collect signals, each luxury unit one consumed only contributes marginally to one's status update. Therefore luxury brands offer goods of declining status and price. This way, they can (1) motivate the high-end consumers to buy more, (2) protect their pricing advantage over the counterfeiters, and (3) protect their core product (i.e., the product with the highest signalling value) and core identity. Put differently, luxury brands find it attractive to expand their product portfolio around their core product to a range of peripheral products (products with decreasing

\footnotetext{
${ }^{1}$ These, in turn, can be informative about one's ranking and position with respect to others in society, such as holding a a high-income job, an elite education, or family roots which facilitate the attainment of these.

${ }^{2}$ Put differently, however high a rank or status one holds, unless it is credibly conveyed and understood by others, it will not give utility to a status-conscious consumer. It is therefore important that status signals and beliefs are consistent among individuals, implying that everyone agrees on the status order of products.
} 
signaling values offered at lower prices). We extend our model to study the characteristics of the market - for instance, we consider what would happen if the luxury brand could not rank its products in their signalling value and had to offer multiple homogeneous products at an identical price. This may hold when the manufacturer lacks the technology to differentiate its goods sufficiently. We find that product line expansion is not a profitable strategy for a brand which fails to differentiate the status signals of its products.

We also study how the market share and the sophistication of the counterfeiter influence the pricing and profitability of the luxury producers. Our findings demonstrate that the threat from a counterfeit market is its quality but not its size. In fact, operating in an environment of high counterfeit activity could benefit luxury brands. The intuition behind this positive effect lies in the interplay of two effects. Status is assessed by others who observe the environment and one's consumption. Presence of counterfeits in a market reduces consumers' prior about the average quality of consumed goods, and increases the incentives to signal status using authentic products from the luxury brand. This is because in a market with high counterfeit activity an authentic product stands out more, and strengthens the signal of one's status. This in turn increases consumers' willingness to pay for that product. Moreover, possession of multiple status goods is a stronger signal of one's status, since the investment into each one of these products (thus, signals) is costly. Altogether, the two effects can jointly increase the profits of the luxury brand. Where a brand loses, however, is when it fails to keep a quality premium over its imitators. If the luxury brand fails to invest in the visible quality of its goods, or if the counterfeiters have access to the same resources to close the quality gap, this in turn reduces the earnings of a luxury manufacturer.

For marketing managers and policy makers, our findings emphasize that the presence of counterfeiters may provide advantages in terms of making the consumption of authentic brands more valuable for status-conscious consumers. This is because when a counterfeit market is present, the prior beliefs about the average quality of products will be lower, and a consumer who cares highly about establishing her status through conspicuous consumption has an incentive to pay higher prices for the luxury brands. Moreover, longer product lines help consumers to make status signals more credible by purchasing additional units from the luxury brand. This implies that the statusconscious consumer will purchase the core product as well as the peripheral (i.e., lower priced and lower status) products of the brand. In the absence of a counterfeit market, the same consumer would have a lower willingness to pay for the luxury brand. 


\subsection{Literature Review}

Utility gained from signalling wealth and status are well established in early works dating back to the 19th century in economics. In his well-cited work "Theory of Leisure Class" (Veblen, 1899; Bagwell et al., 1996), Veblen suggests that the wealthy consume and waste goods with a desire to signal their wealth and elite status, and their need to attain social status stems from the need for social recognition. A significant number of studies in economics, marketing, and psychology focus on understanding the need for status including the use of counterfeits (Wilcox et al., 2009), signalling via non-conformity (Bellezza et al., 2014) and brand prominence (Han et al., 2010) and how firms can take advantage of this need (Chaudhuri and Majumdar, 2006; Ordabayeva and Chandon, 2011; Berger et al., 2011; Ferraro et al., 2013; Wang and Griskevicius, 2014). A stream of studies in marketing focus on status and vice goods investigating their pricing and competitive strategy (Pesendorfer, 1995; Amaldoss and Jain, 2005a,b; Kuksov and Xie, 2012; Yoganarasimhan, 2012; Jain, 2012; Tereyagoglu and Veeraraghavan, 2012; Kuksov and Wang, 2013; Rao and Schaefer, 2013; Amaldoss and Jain, 2015) and offering them as limited edition and scarce goods (Balachander and Stock, 2009). Others consider the effect of the desire to attain status as a motivator for adoption of new products (Van den Bulte and Joshi, 2007). Consumer behavior literature also demonstrated that consumers who feel powerless may choose to consume items of larger sizes, to overcome this feeling and to signal status (Dubois et al., 2012).

Another rich stream in marketing focus on product line extension strategies. Joshi et al. (2016) study product line scope and pricing decisions in a horizontally differentiated duopoly and show that only one firm may prefer to expand scope but profits may be higher for both firms, even in the absence of market size expansion. Broader scope permits that firm to effectively price discriminate by raising prices for its core customers. Randall et al. (1998) study if the inclusion of premium or high-quality products in a product line enhances brand equity or if the presence of low quality products reduces it and show that indeed there is an association between a lower (higher) brand equity and having lower (higher) quality products in the product line. Hamilton and Chernev (2010) study a relevant question, but focusing on the price image of brands. The authors argue that upscale extensions can decrease rather than increase price image, and vice versa for downscale extensions. Others have investigated vertical extensions by studying its impact on profit (Hardie et al., 1994; Draganska and Jain, 2006) and brand positioning (Horsky and Nelson, 1992) and whether luxury brand extensions may invite consumers who are different than the core, or if their presence can dilute the value of the brand (Bellezza and Keinan, 2014).

Qian (2008, 2014a,b) study the impact of counterfeiters in a series of studies. Counterfeiting is the unauthorized manufacturing of goods with the intention to mimic the characteristics of an 
authentic product. These studies offer insights about the macroeconomic consequences of the entry by counterfeiters into a country. While counterfeiting is an activity of theft of intellectual property and must be combated, the influence of counterfeiting activity on firms' marketing strategies are less studied. In the intellectual property of digital goods such as movies and music, whether piracy and illegal sharing of these goods result in any economic harm was the focus of a stream of research. The results from this stream are inconclusive (Givon et al., 1995; Bai and Waldfogel, 2012; Waldfogel, 2012).

Our paper makes two contributions to the existing literature. First, we develop a model allowing consumers to update their beliefs about status in a Bayesian fashion. We demonstrate that unlike goods consumed for utilitarian reasons, status goods can be consumed in multiples if consuming them provides consumers the benefit of signalling status. This construction allows us to compare the items offered by a luxury brand in status and develop optimal pricing strategy for firms based on the status rank of these products. Second, we explicitly study the impact of counterfeits on the product line extension and pricing strategy, which, to our knowledge, have not been studied in the analytical modeling literature in marketing before. Although others before us studied luxury branding and conspicuous consumption in marketing (e.g., Kuksov and Xie, 2012; Tereyagoglu and Veeraraghavan, 2012; Rao and Schaefer, 2013), the study of product line extension and counterfeiter impact are new.

In the rest of the paper, we first start by developing a model in Section 2. We provide our key insights in Section 3 and we extend our benchmark model to test for market conditions and relax model assumptions in Section 4. Finally, in Section 5 we conclude with managerial insights.

\section{Model}

\subsection{Set up}

We consider a market with two outlets $\mathbb{S}=\{A, C\}$ representing the manufacturer of authentic goods and a counterfeiter that produces products which imitate the goods of the authentic brand. Under the authentic manufacturer, we will specifically consider a luxury goods producer whose products are purchased and consumed for visible consumption and status signalling. Each outlet can choose to offer a portfolio of products differentiated in their value of signaling status and price.

Consumers in the market consume goods for their consumption or status signalling value. Goods of outlet $s \in \mathbb{S}$ have an average product quality $q(s)=\mu_{s}$. We assume that the average quality of 
authentic brands' products is greater than that of the counterfeiter: $\mu_{A}>\mu_{C}>0 .{ }^{3}{ }^{4}$ We assume that the public has a common prior about the distribution of the quality $(q)$ of products in the market, which is normal ${ }^{5}$ with mean $\mu_{0}$ and variance $\sigma_{0}^{2}$ :

$$
q \sim N\left(\mu_{0}, \sigma_{0}^{2}\right)
$$

Let $\rho \in(0,1)$ represent the market share of the luxury brand (i.e., the manufacturer of the authentic goods). The prior mean is a weighted average of the qualities of the two outlets, where the weights are determined by each outlet's market share:

$$
\mu_{0}=\rho \mu_{A}+(1-\rho) \mu_{C}
$$

Without additional information, a higher market share of the counterfeiter instills the average belief that a product is more likely to come from the counterfeiter outlet.

The luxury brand determines its retail strategy by determining the size of its portfolio and the prices of the products. The products in the portfolio are represented by an index number: $i \in I=\{1, \ldots, n\}$, where product 1 is defined as the "core product" of a brand. The core product is the staple product of the brand which provides the highest signalling value among the portfolio of products. In line with our set up, luxury brands often consider one (or sometimes multiple) goods as their core products (Dauriz and Tochtermann, 2013). We will consider the existence of a core product not only for the authentic brand but also for the counterfeit.

We further assume that products of higher quality produce more credible signals of status. The purchase and consumption of product $i$ from outlet $s$ enable the consumer to send an unbiased status signal of its true quality $\theta^{i} \mid q(s) \sim N\left(\mu_{s},\left(\sigma^{i}\right)^{2}\right)$, where $1 / \sigma^{i}$ is the precision of product $i$ 's signal. Conditional on the product quality $q$, signals are independent across the product line, i.e., over $i$. The assumption on $\sigma^{i}$ implies that the information carried about product quality holds similar uncertainty for products of comparable rank although the counterfeits are on average of lower quality ${ }^{6}$. Product $i$ 's signal precision increases with the ranking of the product ${ }^{7}$ :

\footnotetext{
${ }^{3}$ The quality of a counterfeiter's product can be higher than the quality of an authentic brand's product, in realization.

${ }^{4}$ Since each counterfeit good is a lower quality imitation of a luxury good, consumers make a comparison between the goods without considering horizontal match characteristics.

${ }^{5}$ Although the model can be extended to incorporate alternative prior distributions, a conjugate prior provides a closed-form expression for the posterior and a clear intuition on how a likelihood function updates a prior distribution.

${ }^{6}$ This assumption can easily be extended to incorporate the case where authentic products send more precise signals than counterfeits. For instance, we can separate the signals from two outlets such that $\sigma_{A}^{i}>\sigma_{C}^{i}$, without compromising our findings. This modeling change would in fact reinforce the justification for the luxury brand to invest into quality.

${ }^{7}$ Throughout the paper, a higher ranked product will indicate a product with a higher status signal, or a product closer to the core. The products closer to the core product have a lower $i$.
} 


$$
\sigma^{i}<\sigma^{j}<1, \forall i>j
$$

Counterfeits imitate the products offered by the luxury brand, providing an alternative for each product the brand offers (Eisend and Schuchert-Güler, 2006). We assume that consumers' decision to purchase an authentic good or a counterfeit imitation is a deliberate one ${ }^{8}$. Here we also make a mild assumption with respect to the production cost, in that the marginal costs of production for the luxury brand is weakly higher than that of the counterfeiter for each product $i: c_{A}^{i} \geq c_{C}^{i} \geq 0$.

We consider a mass 1 of consumers who are heterogeneous with respect to how much they care about signalling status. Each consumer is allowed to buy up to one unit of each product $i$. The type of each consumer is represented by the parameter $\alpha$ which calibrates the importance she places on signalling status. We assume that $\alpha$ is distributed by a truncated log-concave distribution $F(\cdot)_{\mid 0<\alpha<1}$ and a higher $\alpha$ implies that the consumer has a higher desire to signal status. This would imply, equivalently, that the consumer has higher willingness to pay for a product which emits status signals compared to another customer who cares relatively less about signalling status. We therefore also interpret it as a price sensitivity parameter. We assume that the distribution of $\alpha$ is a common knowledge, but the status sensitivity of an individual consumer $(\alpha)$ is her private information unobservable by others.

Without loss of generality, we assume that there are two consumer segments: those who mainly consume goods to signal status (high-end consumption needs, status-conscious consumers) and others who consume goods for their consumption value (low-end consumption needs, consumption orientation). The two segments are determined based on a threshold $\left(\alpha^{*}\right)$, where the high-end segment cares relatively more about status $\left(\alpha \geq \alpha^{*}\right)$ than the low-end consumer $\left(\alpha<\alpha^{*}\right)$. Without loss of generality, we link the market share of the luxury brand with the fraction of high-end segment: $\rho \equiv 1-F\left(\alpha^{*}\right)$. Presence of the low-end consumers who consume imitation products influences how clearly a high-end consumer can signal status, because their consumption influences public's prior beliefs about the average quality of an observed product in the market.

We represent the utility from signalling status and consumption in a stylized form. The high-end consumer segment gains utility mainly from signalling status to others. They also implicitly gain utility when a product is of higher quality:

$$
\alpha \mathbb{E}\left(\mu_{1} \mid k, s\right)-\sum_{i=1}^{k} p_{s}^{i} .
$$

\footnotetext{
${ }^{8}$ It is possible that in some markets consumers buy counterfeits because of deceptive sales practices, believing that a product is authentic. In this study, we abstract away from consumers buying counterfeits unknowingly, and just focus on the intentional purchase of counterfeits to yield consumption value.
} 
where $\mu_{1}$ denotes the posterior mean of quality $q$. In this expression, the expected quality from observing a consumption of $k$ items from outlet $s$ is the term $\mathbb{E}\left(\mu_{1} \mid k, s\right)$ and it is the perceived status of the individual by others. So in this setting, a perception of status is created as a joint function of the characteristics of the products which is proportional to the number of the items purchased. The consumer's emphasis on status $(\alpha)$ influences how much the perception of others yields them utility. We also define the utility of not buying any products to be equal to the public's prior, i.e., $\mathbb{E}\left(\mu_{1} \mid 0, s\right)=\mu_{0}, \forall s \in\{A, C\}$, for all consumers.

The low-end consumer segment's utility is mainly utilitarian and relies on the characteristics of the brand (its quality). The utility also indirectly increases when the consumer cares more about status and consumes a close copy of a higher ranked product:

$$
\sum_{i=1}^{k}\left(\frac{\alpha \mu_{C}}{i}-p_{C}^{i}\right) .
$$

The division with the status rank of the product in the denominator allows us to construct a preference for the low-end consumers to care about status and consuming imitations of higher ranked luxury brands. Consumers have an order of preference, even for the counterfeiter's portfolio. Notice that in our setting both consumer segments care about the quality of the product and status. ${ }^{9}$ Moreover, we will also prove that given the utility formulation, low-end consumers will prefer to buy from the counterfeiter over buying from the luxury brand.

Importantly, our setting allows products to be differentiated vertically. Vertical differentiation, or an agreement among public about the quality of the observed products is important for consumers to reliably signal their status. If consumers carried different beliefs about which product constitutes a higher status signal, there may be no agreement on the value of goods. In such an environment, signalling status is not meaningful because the value of each product varies from consumer to consumer. To properly study status signalling and derive equilibrium results, it is important that individuals have consistent beliefs about status signals. When consumers all agree on which products are more preferred, such a set up is most suitable for a vertical differentiation model. This construction is an important feature of our model, and we consider it to be a contribution to the literature on signalling and luxury consumption.

Next, we will introduce the timing of the game and establish how consumers update their beliefs about the status of others using the setup we have developed.

\footnotetext{
${ }^{9}$ We will show that we could obtain similar conclusions by endogenizing segmentation in Section 4.
} 


\subsection{Timing of the Game}

The timing of the game is as follows:

1. Given their cost functions, the luxury brand chooses the length of the product line $n$ and the decision is publicly observed by the counterfeiter and all consumers.

2. The luxury brand $(A)$ and the counterfeiter $(C)$ choose an optimal pricing strategy for each product $i$ they offer. ${ }^{10}$

3. Observing the market prices for each product, consumers choose to shop from the luxury brand or the counterfeiter and buy $k$ different products ${ }^{11}$.

4. Consumers consume the products. Consumption automatically sends a sequence of signals $\left\{\theta^{i}\right\}_{i \leq k}$ drawn from the product's distribution governed by the signalling technology $\theta^{i} \mid q(s) \sim$ $N\left(\mu_{s},\left(\sigma^{i}\right)^{2}\right)$.

5. The public observes all the signals and makes a judgment using the Bayes rule about the average product quality a consumer bought and makes an assessment about the consumer's social status.

\subsection{Signalling Status}

We assume that consumers have a common prior about the distribution of the quality of products, $\mu_{0} \sim N\left(\mu_{0}, \sigma_{0}^{2}\right)$, consistent with the market primitives. This prior will help them to construct beliefs about the status of others. ${ }^{12} 13$ By Bayes' rule (DeGroot 1970), after observing $k$ signals, the posterior mean $\mu_{1}$ is a weighted average of the prior mean $\mu_{0}$ and the observed signals $\theta$ from one's consumption:

$$
\mu_{1} \mid \theta(k)=\frac{\sum_{i=1}^{k}\left[\frac{\theta^{i}}{\left(\sigma^{i}\right)^{2}}\right]+\frac{\mu_{0}}{\sigma_{0}^{2}}}{\sum_{i=1}^{k} \frac{1}{\left(\sigma^{i}\right)^{2}}+\frac{1}{\sigma_{0}^{2}}}, \theta(k)=\left\{\theta^{i}\right\}_{i \leq k}
$$

In line with Bayesian updating, the less accurate a signal is, the more weight is assigned to the prior quality. More accurate signals from one's conspicuous consumption, on the other hand, allows the beliefs to be more highly influenced by the consumption itself.

\footnotetext{
${ }^{10}$ We assume that outlets can only charge one price for each product $i$ regardless of their realized quality.

${ }^{11}$ It is reasonable to assume that consumers buy only one of each product since buying a duplicate will not provide a value justifying its price.

${ }^{12}$ Notice that signalling status is about the perceptions of others rather than what one believes of his own status to be. For signalling to work, it is important to have consumer beliefs that are consistent about what constitutes high quality. If consumers have different beliefs about which items signal status, then brands cannot establish status signals credibly.

${ }^{13}$ Consumers may be interested in observing status signals of others for a range of reasons specifics of which are not modeled in our framework, including giving a job offer, finding a romantic match, or making friends.
} 
Since the high-end consumer segment cares about signalling status, they also care about making their status image as credible as possible. To increase the credibility, they can increase their consumption by purchasing additional goods from the luxury brand's portfolio. This way, first, they increase the cost on others to match one's status, and second, they make their own status less noisy. The more authentic (counterfeit) products of the same brand a consumer buys, the more (less) credible his/her signals are, because (1) the weight given to the prior decreases in the number of goods purchased $(k)$, and (2) signals are informative about the true quality of the brand. To see this more clearly, we represent the uncertainty in quality when consumption of $k$ products is observed as:

$$
\sigma_{1}^{2}(k) \equiv\left[\sum_{i=1}^{k} \frac{1}{\left(\sigma^{i}\right)^{2}}+\frac{1}{\sigma_{0}^{2}}\right]^{-1}
$$

which is decreasing in $k$. And the posterior mean conditional on observing $(k+1)$ signals of products becomes:

$$
\mu_{1} \mid \theta(k), \theta^{k+1}=\frac{\frac{\mu_{1} \mid \theta(k)}{\sigma_{1}^{2}}+\frac{\theta^{k+1}}{\left(\sigma^{k+1}\right)^{2}}}{\frac{1}{\sigma_{1}^{2}}+\frac{1}{\left(\sigma^{k+1}\right)^{2}}} .
$$

If the signal from the consumption of the $(k+1)^{t h}$ good exceeds the expected status perception from the first $k$ goods, then the consumer will give a more credible signal overall with $k+1$ goods. Notice that

$$
\begin{cases}\mu_{1}\left|\theta(k), \theta^{k+1} \geq \mu_{1}\right| \theta(k) & \text { if } \theta^{k+1} \geq \mu_{1} \mid \theta(k) \\ \mu_{1}\left|\theta(k), \theta^{k+1}<\mu_{1}\right| \theta(k) & \text { if } \theta^{k+1}<\mu_{1} \mid \theta(k)\end{cases}
$$

The number of products a consumer buys is determined together with how much she cares about her status and the cost of buying an additional product. We will use this relationship to establish the marginal returns from consuming additional products.

Lemma 1. The marginal increment in the expected status from consuming an additional good from the same outlet decreases in the size of the purchased product portfolio $k$ :

$$
\mathbb{E}\left(\mu_{1} \mid k+1, s\right)-\mathbb{E}\left(\mu_{1} \mid k, s\right) \leq \mathbb{E}\left(\mu_{1} \mid k, s\right)-\mathbb{E}\left(\mu_{1} \mid k-1, s\right), \forall k \geq 1
$$

Lemma 1 suggests that there are decreasing returns to making additional purchases. Although the overall credibility of the status signal increases, it increases at a lower rate with each additional product purchased. The decreasing marginal utility from signalling value is important because it 
allows the authentic brand to market its core product without the threat of cannibalization from its peripheral goods in the product line. This implies that, for instance, Hermès has an incentive to offer its handbags rather than offering key chains, or Patek Phillippe would be able to protect its watchmaker identity. Put differently, this lemma also helps to explain why we do not see luxury brands abandoning their core products to sell entirely different goods.

Upon observing consumption, consumers update their beliefs about the consuming person's status. Since in our framework status is attained by consuming products which are believed to be of high quality, we investigate the posterior belief about the product quality conditional on receiving an additional signal. The updated belief can be represented as a weighted average of the previous belief (without the new information coming from the consumption signal) and the value of the new signal, while the relative weights depend on the precision of this signal. As noted earlier, although consuming a set of goods from the same outlet makes the status beliefs more precise, the marginal value of an additional signal is decreasing in the number of products consumed. While each product from outlet $s$ is expected to have the same average quality $\mathbb{E}\left(\theta^{k+1} \mid s\right)=\mathbb{E}\left(\theta^{k} \mid s\right)=\mu_{s}$, the additional weight given to the $(k+1)^{t h}$ signal is lower than the $k^{\text {th }}$ signal because the former is less precise $\left(\sigma^{k+1}>\sigma^{k}\right)$. Consequently, the marginal change in the average expected belief by consuming the $(k+1)^{t h}$ good becomes:

$$
\begin{aligned}
\mathbb{E}\left(\mu_{1} \mid k+1, s\right)-\mathbb{E}\left(\mu_{1} \mid k, s\right) & =\left[\mu_{s}-\mathbb{E}\left(\mu_{1} \mid k, s\right)\right] \frac{\frac{1}{\left(\sigma^{k+1}\right)^{2}}}{\sum_{i=1}^{k+1} \frac{1}{\left(\sigma^{i}\right)^{2}}+\frac{1}{\sigma_{0}^{2}}} \\
& =\left[\mu_{s}-\frac{\left.\mu_{s} \sum_{i=1}^{k} \frac{1}{\left(\sigma^{i}\right)^{2}}+\frac{\mu_{0}}{\sigma_{0}^{2}}\right] \frac{\frac{1}{\left(\sigma^{k+1}\right)^{2}}}{\sum_{i=1}^{k} \frac{1}{\left(\sigma^{i}\right)^{2}}+\frac{1}{\sigma_{0}^{2}}}}{\sum_{i=1}^{k+1} \frac{1}{\left(\sigma^{i}\right)^{2}}+\frac{1}{\sigma_{0}^{2}}}\right. \\
& =\left(\mu_{s}-\mu_{0}\right) \cdot \frac{\sigma_{1}^{2}(k)}{\sigma_{0}^{2}} \cdot \frac{\sigma_{1}^{2}(k)}{\sigma_{1}^{2}(k)+\left(\sigma^{k+1}\right)^{2}}
\end{aligned}
$$

where $\sigma_{1}^{2}(k)$ follows the representation given in Equation 1. The marginal benefits from consuming the $(k+1)^{t h}$ product is higher when prior mean $\left(\mu_{0}\right)$ is lower. Given the difference in average quality and the prior mean in the society $\left(\mu_{s}-\mu_{0}\right.$, the first term), the marginal value of additional consumption is proportional to the product of the relative weight given to the prior $\left(\frac{\sigma_{1}^{2}(k)}{\sigma_{0}^{2}}\right.$, second term) and the relative weight associated with the $(k+1)^{t h}$ signal $\left(\frac{\sigma_{1}^{2}(k)}{\sigma_{1}^{2}(k)+\left(\sigma^{k+1}\right)^{2}}\right.$, third term), both of which are decreasing in $k$. Consuming a lower ranked product provides lower marginal benefits and less precise prior beliefs about product quality reduce the benefit from additional consumption of products. 


\subsection{Consumer Choice}

\subsubsection{High-end Segment}

We start the analysis by demonstrating the choices of the high-end consumer segment. Recall that these consumers are interested in signalling their status through consumption of high quality products. The problem of consumer $\alpha$ is given by:

$$
\max _{k, s} \alpha \mathbb{E}\left(\mu_{1} \mid k, s\right)-\sum_{i=1}^{k} p_{s}^{i}
$$

where the consumer is simultaneously deciding on the outlet and how many products to purchase. Conditional on the prices charged by each outlet for each product, she chooses an outlet-quantity pair $(s, k)$ which maximizes her utility net of prices. The condition which incentivizes her purchase of the $k^{\text {th }}$ product is the added net utility upon having purchased $(k-1)$ products:

$$
\mathbb{E}\left(\mu_{1} \mid k, s\right)-\mathbb{E}\left(\mu_{1} \mid k-1, s\right) \geq \frac{1}{\alpha} p_{s}^{k}\left(\mu, \sigma^{k}\right), \forall k \geq 1 .
$$

Conditional on owning $(k-1)$ products, a consumer is willing to buy the $k^{\text {th }}$ product if and only if the marginal status signalling benefit of owning the $k^{\text {th }}$ product exceeds its price, multiplied by the price sensitivity markup $\frac{1}{\alpha}$. Put differently, a consumer is willing to buy the $k^{\text {th }}$ product when its cost is smaller than the benefit she gains in improving her status perception. A low price $\left(p_{s}^{k}\right)$ or a high desire to display status (high $\alpha$ ) makes it easier to satisfy the constraint (3). The role of $\alpha$ here makes it easier to see why we also refer to it as the price sensitivity of a consumer: a consumer who cares highly about signalling status will be willing to accept a higher price to buy the additional product.

In the rest of our analysis, the expression for the marginal benefit of buying the $k^{\text {th }}$ good will be commonly used. We will simply call this difference the signalling value of the $k^{\text {th }}$ good, and introduce a parameter to make the expressions easier to follow for the reader. From Equation 2, let

$$
\beta_{s}^{k} \equiv \frac{1}{\mathbb{E}\left(\mu_{1} \mid k, s\right)-\mathbb{E}\left(\mu_{1} \mid k-1, s\right)}=\frac{1}{\left(\mu_{s}-\mu_{0}\right) \frac{\sigma_{1}^{2}(k-1)}{\sigma_{0}^{2}} \cdot \frac{\sigma_{1}^{2}(k-1)}{\sigma_{1}^{2}(k-1)+\sigma_{k}^{2}}} \text { for all } k \leq n
$$

denote the inverse of marginal signalling value after buying the $k^{\text {th }}$ product from outlet $s$. A high $\beta_{s}^{k}$ implies that the purchase of the $k^{t h}$ product yields little signalling benefit to a consumer. Therefore consumers would prefer to buy products which have a lower $\beta_{s}^{k}$.

Lemma 2. (Product Price-Status Signalling Order) The marginal consumer in the high-end 
segment buys multiple products from the same outlet if and only if the prices of the products are decreasing in their signalling rank.

Recall that the signalling value of consuming an additional good is decreasing monotonically. This suggests that unless the prices follow the same trend (decrease monotonically), there are no incentives for the marginal consumer to buy additional products. A deviation from this order would imply that portfolio expansion by the brands is wasteful due to potential drop in the sales of existing products in the line ${ }^{14}$.

Proposition 1. (Competitive Advantage in Pricing) The difference in prices between two sequentially ranked products can be smaller for the luxury brand compared to the difference in prices of the two sequentially ranked products of the counterfeiter. This means that luxury brands have a narrower spacing in pricing and require less drastic price discounting as they move from their core product to peripheral products in their signalling order.

Proposition 1 holds because high-end consumers enjoy status (i.e., have higher $\alpha$ ) and for any given price of the $k^{\text {th }}$ product, (3) is less likely to bind for the luxury brand compared to the counterfeiter. When the product line length is identical between the luxury brand and the counterfeiter, we should observe a higher degree of price dispersion for the counterfeit products, showing a greater price gap in offerings compared to the luxury brand. For the luxury brand managers, this finding emphasizes their pricing power over the counterfeiters: they can maintain higher prices on average for each good even if the counterfeiter were to offer an imitation for each one of them. If the consumers on average became less concerned with status, this pricing advantage would erode.

Lemma 3. (High-end Consumer Preference for Luxury) High-end consumers buy from outlet $s$ if and only if the posterior mean of its quality distribution is above the mean of the prior. Consequently, they have an incentive to buy only from the luxury brand.

Equation 2 shows that the sign of the marginal value of buying the $k^{\text {th }}$ good from outlet $s$ depends on the sign of $\left(\mu_{s}-\mu_{0}\right)$. In line with the desire of the high-end consumers to signal status, Lemma 3 suggests that any consumption by the consumers in this segment must enhance their image compared to the status they would have without any consumption. Recall that the prior beliefs are centered around a weighted average of the mean qualities of the luxury brand's and the counterfeiter's goods, $\mu_{0}=\rho \mu_{A}+(1-\rho) \mu_{C}$. Since the average quality of the luxury goods is higher than that of the counterfeiter $\left(\mu_{A}>\mu_{C}\right)$, the difference between the mean qualities of the luxury

\footnotetext{
${ }^{14}$ We will prove this implication on the single-price setting formally in the Section 4.
} 
good and the average good in the market $\left(\mu_{A}-\mu_{0}\right)$ is positive, while that between the counterfeiter and the average good $\left(\mu_{C}-\mu_{0}\right)$ is negative. In order to increase their status perceptions, high-end consumers have an incentive to buy only from the luxury brand and not from the counterfeiter. This is because no matter how attractive the price of a counterfeit good is, ex ante, visible consumption of it always lowers the posterior quality perception, or status. Consequently, only the low-end but not the high-end consumers buy the counterfeit goods.

Lemma 4. (Ranking Order in Status Goods Consumption) If the difference in signalling value is greater compared to the difference in prices across two consecutively ranked products in the luxury brand portfolio, that is, if

$$
\frac{\beta_{A}^{k}}{\beta_{A}^{k-1}} \geq \frac{p_{A}^{k-1}}{p_{A}^{k}}, \forall 1<k \leq n
$$

consumers who buy the lower ranked product also buy all the products ranked above it.

Lemma 4 suggests that consumption of luxury products follows a signalling and price order. Consumers who care about signalling status will first buy the core product and then gradually choose to add other peripheral products to their consumption, until the cost of purchasing a product exceeds its marginal signalling benefit. For manufacturers, it is important that there is a preference order to consumption, otherwise product line expansion is not meaningful since some products would not find adequate demand.

\subsubsection{Low-end Segment}

For the low-end segment who cares less about signalling status, the main driver of consumption is the quality of a product (e.g., longer product life, sturdiness, better materials, better functionality). These consumers solve the problem of selecting $k$ products such that their utility will be maximized considering the quality of a product ${ }^{15}$ :

$$
\max _{k} \sum_{i=1}^{k}\left(\frac{\alpha \mu_{C}}{i}-p_{C}^{i}\right) .
$$

The expression suggests that all else being identical, a consumer would prefer a higher quality product closer to the core, at a lower price. A consumer who cares relatively more about status, all else being equal, enjoys the product more. Here the term in the denominator considers the

\footnotetext{
${ }^{15}$ We also discuss in Section 4.2 the case where consumers in high and low-end segments have the same form of utility function and segmentation is endogenous.
} 
marginally decreasing utility attained from the lower status signalling (lower ranked items). The division by the ranking order of the products allows us to introduce the status consideration for the consumers, independently of the quality. According to this utility function, a low-end consumer endowed with $\alpha$ is willing to buy a counterfeit product $i$ if and only if its price is lower than a threshold status-quality-ranking value:

$$
p_{C}^{i} \leq \frac{\alpha \mu_{C}}{i}
$$

We will use the expressions derived for the utility functions and the threshold values which motivate consumption to derive the optimal product line policies for the brand next.

\section{Product Line Strategy}

We start the analysis by discussing the product line strategy for the luxury brand. ${ }^{16} 17$ The profit function of the luxury brand which offers $n$ products can be formally expressed as the product of the profit from the $i^{\text {th }}$ ranked product and its demand, subject to the constraint that the product follows the signaling value and pricing order laid out in Lemma 4:

$$
\begin{aligned}
\Pi(A, n) & =\sum_{i=1}^{n}\left[\left(p_{A}^{i}-c_{A}^{i}\right) D_{i}\left(p_{A}^{i}\right)\right] \\
\text { s.t. } & \\
\beta_{A}^{k} p_{A}^{k} & \leq \beta_{A}^{k+1} p_{A}^{k+1} \text { for all } 1 \leq k \leq n
\end{aligned}
$$

where $D_{i}\left(p_{A}^{i}\right)$ is the demand for product $i$ sold at price $p_{A}^{i}$. In order to avoid trivial results, we focus on the case where the most status-sensitive consumers should at least buy one authentic product. Moreover, the production cost of the core product should not exceed the willingness-to-pay of the most status-sensitive consumers $(\alpha=1)$ by construction. Hence we make the assumption that $c_{A}^{1} \leq\left(\beta_{A}^{1}\right)^{-1}$ throughout our analysis ${ }^{18}$. In this case, the demand for each product $k(\leq n)$ is

\footnotetext{
${ }^{16}$ The counterfeiter mimics the products of the luxury brand, therefore will have an identical product line length.

${ }^{17}$ Notice that differentiation along quality is another possibility, but a riskier one for a luxury brand. If the quality of the goods decreased with the size of the portfolio, the brand would open itself to the threat of diluting its quality perception. Therefore we study a strategy where the brand differentiates along products while keeping the quality uniform.

${ }^{18}$ Notice that for $\alpha=1, \alpha \beta_{A}^{1^{-1}}=\beta_{A}^{1^{-1}}$ is the highest price a consumer would be willing to pay for the core. This price should not be lower than the cost of production, i.e., $c_{A}^{1}$ for the firm to produce the product.
} 


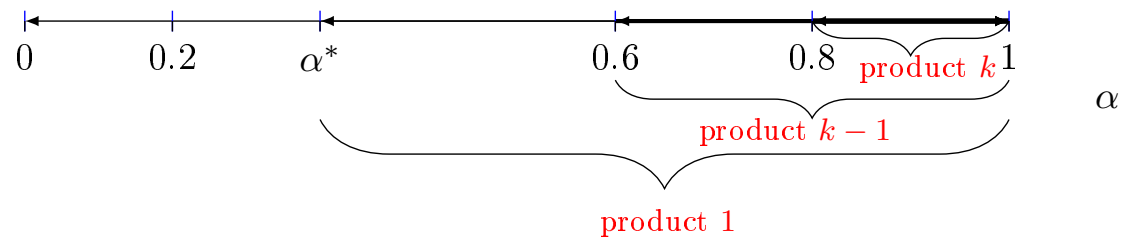

Figure 1: Example for the Demand Structure for the Luxury Brand

described by the following expressions for the luxury brand and the counterfeiter, respectively:

$$
\begin{aligned}
D_{k}\left(p_{A}^{k}\right) & =1-F\left(\max _{l=1, \ldots, k}\left\{p_{A}^{l} \beta_{A}^{l}\right\}\right) \\
& =1-F\left(p_{A}^{k} \beta_{A}^{k}\right) \\
D_{k}\left(p_{C}^{k}\right) & =F\left(\alpha^{*}\right)-F\left(\frac{k p_{C}^{k}}{\mu_{C}}\right),
\end{aligned}
$$

The demand of each product is fragmented conditional on the ranking order captured by each market. Figure 1 demonstrates an example demand structure on the unit interval. The total demand corresponds to the mass of consumers endowed with the status consciousness of $\alpha$ above the threshold value $\alpha^{*}$. Starting with the marginal consumer who finds it worthwhile to invest only in the core product, as the status concerns of the consumers increase, they gradually expand their basket size. The consumer with the highest status concern $(\alpha=1)$ buys $k$ products, starting from the core, reaching to the $k^{\text {th }}$ product which satisfies the condition given in Lemma 1. Since high-end consumers who are willing to buy lower-ranked products must already own higher-ranked products, the demand for lower-ranked products (equivalently, the number of products purchased, $k$ ) must be a subset of demand of higher-ranked ones. Note that if $F(\cdot)$ is a Uniform distribution on [0,1], the demand function becomes linear in price. We will focus on this special case to derive the key insights.

\subsection{Pricing of Products}

\subsubsection{Authentic Brand}

Let the luxury brand's optimal price vector be $\mathbf{p}_{A}=\left(p_{A}^{1}, p_{A}^{2}, \ldots, p_{A}^{n}\right)$ for items 1 to $n$ in the portfolio. The prices of the $n$ products can be obtained by solving a system of $n$ first order conditions $(1 \leq$ $k \leq n)$ :

$$
0=\left[1-F\left(\beta_{A}^{k} p_{A}^{k}\right)\right]-\left(p_{A}^{k}-c_{A}^{k}\right) \beta_{A}^{k} f\left(\beta_{A}^{k} p_{A}^{k}\right)+\left(\lambda_{k-1} \cdot \mathbf{1}_{\{\mathbf{k} \geq \mathbf{2}\}}-\lambda_{k} \cdot \mathbf{1}_{\{\mathbf{k} \leq \mathbf{n}-\mathbf{1}\}}\right) \cdot \beta_{A}^{k}
$$


subject to $(n-1)$ signal value to price ratio constraints from Lemma 4 :

$$
\begin{aligned}
0 & =\lambda_{k}\left(\beta_{A}^{k+1} p_{A}^{k+1}-\beta_{A}^{k} p_{A}^{k}\right) \\
0 & \leq \lambda_{k} \\
0 & \leq \beta_{A}^{k+1} p_{A}^{k+1}-\beta_{A}^{k} p_{A}^{k} \\
\forall k, 1 & \leq k \leq n-1
\end{aligned}
$$

where $\mathbf{1}_{\{\cdot\}}$ is the indicator function that equals to 1 if the condition in the curly bracket holds and 0 otherwise. The signal values are defined in line with Equation 4:

$$
\beta_{A}^{k}=\frac{1}{\left(\mu_{A}-\mu_{0}\right) \frac{\sigma_{1}^{2}(k-1)}{\sigma_{0}^{2}} \cdot \frac{\sigma_{1}^{2}(k-1)}{\sigma_{1}^{2}(k-1)+\sigma_{k}^{2}}} \text { for all } k \leq n
$$

Without loss of generality, to provide the key insights, we will assume that the distribution shaping the demand function $F(\cdot)$ is a Uniform distribution with support on $[0,1]$. Under Uniform distribution, the system of equations reduces to

$$
\begin{aligned}
& 0=1-2 \beta_{A}^{1} p_{A}^{1}+\left(c_{A}^{1}-\lambda_{1}\right) \beta_{A}^{1} \\
& 0=1-2 \beta_{A}^{2} p_{A}^{2}+\left(c_{A}^{2}+\lambda_{1}-\lambda_{2}\right) \beta_{A}^{2} \\
& \vdots \\
& 0=1-2 \beta_{A}^{n} p_{A}^{n}+\left(c_{A}^{n}+\lambda_{n-1}\right) \beta_{A}^{n}
\end{aligned}
$$

s.t.

$$
\begin{aligned}
0 & =\lambda_{k}\left(\beta_{A}^{k+1} p_{A}^{k+1}-\beta_{A}^{k} p_{A}^{k}\right) \\
0 & \leq \lambda_{k} \\
0 & \leq \beta_{A}^{k+1} p_{A}^{k+1}-\beta_{A}^{k} p_{A}^{k} \\
\forall k, 1 & \leq k \leq n-1 .
\end{aligned}
$$

To understand the optimal pricing and product length, we can solve this system of equations subject to the constraint set. We provide the solution in the Appendix and summarize the two possible pricing strategies for luxury brand portfolios, conditional on the relative signal value of consecutive goods to their production cost. We refer to these cases as the high and low economies of scope. According to Panzar and Willig (1981), there are economies of scope when it is less costly 
to combine two or more products in one firm than to produce them separately. Similarly, we will compare relative cost $\left(c_{A}^{k+1} / c_{A}^{k}\right)$ of expanding the product line to one more good to the relative benefit provided to consumers $\left(\beta_{A}^{k} / \beta_{A}^{k+1}\right)$ which drives their willingness to pay. A firm which can offer high status benefits to customers by expanding its product line relative to the cost of expansion should establish longer product lines.

Case 1 (High Economies of Scope): The first case we analyze is the environment where the relative costs of producing one more product is lower than the signalling benefits a consumer can obtain from the additional product in the line, formally when $\left(\frac{c_{A}^{k+1}}{c_{A}^{k}} \leq \frac{\beta_{A}^{k}}{\beta_{A}^{k+1}}\right)$ holds for all $k, 1 \leq k \leq n-1$. We prove in the Appendix that in Case 1, all the multipliers are strictly positive: $\lambda_{k}>0, \quad 1 \leq k \leq n-1$, which implies that all the inequality constraints in Equation (5) are binding. Let $m$ be the "effective price" of a good that divides the actual price by its signalling benefit $m:=p_{A}^{1} \beta_{A}^{1}=p_{A}^{2} \beta_{A}^{2}=\ldots=$ $p_{A}^{n} \beta_{A}^{n}$. Substituting into the first $n-1$ first order conditions to solve for the Lagrange multipliers $\lambda$ yields:

$$
\lambda_{k}=\sum_{i=1}^{k}\left[c_{A}^{i}+\frac{(1-2 m)}{\beta_{A}^{i}}\right] \quad \forall k, 1 \leq k \leq n-1 .
$$

And the last first order condition yields

$$
\lambda_{n-1}=-c_{A}^{n}-\frac{1-2 m}{\beta_{n}} .
$$

Combining the last two equations for $\lambda_{n-1}$, we derive $m=\frac{1}{2}+\frac{\sum_{i=1}^{n} c_{A}^{i}}{2 \sum_{i=1}^{n} \frac{1}{\beta_{A}^{i}}}$ and the optimal price of product $k$ expressed in terms of the signalling value of the product is given by:

$$
p_{A}^{k}= \begin{cases}\frac{1}{2 \beta_{A}^{k}}+\frac{\sum_{i=1}^{n} c_{A}^{i}}{2 \sum_{i=1}^{n} \frac{\beta_{A}^{k}}{\beta_{A}^{i}}} & \text { if } m \geq \alpha^{*} \\ \frac{\alpha^{*}}{\beta_{A}^{k}} & o / w\end{cases}
$$

Demand is given by

$$
D_{k}\left(p_{A}^{k}\right)= \begin{cases}1-m=\frac{1}{2}-\frac{\sum_{i=1}^{n} c_{A}^{i}}{2 \sum_{i=1}^{n} \frac{1}{\beta_{A}^{i}}} & \text { if } m \geq \alpha^{*} \\ 1-\alpha^{*} & \mathrm{o} / \mathrm{w}\end{cases}
$$

Case 2 (Low Economies of Scope): The second case we consider is when the cost of expanding the product line is high relative to the benefits delivered to consumers, where $\frac{c_{A}^{k+1}}{c_{A}^{k}}>\frac{\beta_{A}^{k}}{\beta_{A}^{k+1}}$ holds 
for all $1 \leq k \leq n-1$. In this case, the cost of adding the next product to the line is greater than its additional signalling benefits. We prove in the Appendix that the solution requires all Lagrange multipliers to be set to zero, that is, $\lambda_{1}=\lambda_{2}=\ldots=\lambda_{n-1}=0$ and the prices of products are given by:

$$
p_{A}^{k}=\min \left\{\frac{1}{2 \beta_{A}^{k}}+\frac{c_{A}^{k}}{2}, \frac{\alpha^{*}}{\beta_{A}^{k}}\right\}
$$

Demand is given by:

$$
D_{k}\left(p_{A}^{k}\right)= \begin{cases}\frac{1}{2}-\frac{c_{A}^{k} \beta_{A}^{k}}{2} & \text { if } c_{A}^{k} \beta_{A}^{k} \geq 2 \alpha^{*}-1 \\ 1-\alpha^{*} & \mathrm{o} / \mathrm{w}\end{cases}
$$

Notice that the prices of the products take a value proportional to their signalling value and their marginal cost of production. When $c_{A}^{k} \beta_{k} \geq 2 \alpha^{*}-1$, an increase in either of these terms results in an increase in the prices and a decrease in the demand. Compared to Case 1, the difference between the pricing and the demand of the two cases is how the signals of the products in the line influence each other's value. In Case 1, the price of each product is influenced by the signalling values of the other purchased products. In Case 2, each product's signalling value only influences its own price and demand. We stress this difference in the following proposition and discussion.

Proposition 2. (Optimal Pricing) A luxury brand may optimally take a portfolio approach or not in pricing its products depending on whether the marginal cost declines faster than the marginal signalling value moving from the core to peripheral products. When it does, it is optimal for the luxury brand to charge prices such that the signal values of all products in a line influence each other. When it does not, optimal pricing calls for pricing goods independently based on their individual signalling value.

Focusing on how the signalling benefit to cost ratio of two consecutively ordered products changes $\left(\frac{c_{A}^{k+1}}{c_{A}^{k}} \leq \frac{\beta_{A}^{k}}{\beta_{A}^{k+1}}\right)$, Cases 1 and 2 compare a luxury brand with sufficient economies of scope to another without it. The proposition suggests that there are two optimal pricing regimes for luxury brands, conditional on their costs and benefits from product line extension. When the signalling benefit to cost ratio is increasing in $k$ (Case 1 ), a manager has to price each product considering the relative position of each product in the product portfolio. That is, prices are strategically set considering the relative signalling value and costs of all the other products in the product line. If the opposite holds (Case 2), each product is priced according to its individual signal value and cost. The prices of the products in this case are independent. In both cases, the first (core) product a firm sells to each consumer is priced the highest independent of its consumption value; and the unit price falls 
for every extra product a consumer purchases. ${ }^{19}$

A luxury brand which can take advantage of economies of scope (Case 1) will offer an identical effective price $m$ (actual price over the signal value) for all its products in the line so that every consumer who shops from the luxury brand is willing to buy all the products it offers. Therefore, the actual price falls for a product with a lower rank as its signalling value falls. Since the effective price aggregates information on the cost of all products in the line, additional cost of producing any product in the line influences the price of another good indirectly. For another brand with lower economies of scope, the costs of producing additional products will be relatively high and thus it has to set a higher effective price for lower ranked products as opposed to that of the core product. This indicates that the brand has a narrower profit margin for each additional product in the line. As a result, some high-end consumers buy one product while others buy multiple products, but only the most status-conscious consumers will buy all the products offered by the luxury brand.

\subsection{Impact of Counterfeit Activity on the Luxury Brand}

Counterfeiting activity is considered a problem for most luxury brands, but unfortunately, little is known or characterized about how a consumer's status signals are influenced by the increased counterfeit activity in the market. This question of course ties directly to the performance of luxury brands.

First, let's analyze what happens to how visibly a consumer can distinguish his status as the market share of counterfeiter $(1-\rho)$ increases. As the market is crowded out by the counterfeits, the (public's) prior on the average quality of an observed good $\mu_{0}$ declines. Put differently, a higher market share of the counterfeiter instills the average belief that a product is more likely to come from the counterfeiter outlet. In turn, any product that is of higher quality will become easier to distinguish from others in that $\left(\mu_{A}-\mu_{0}\right)$ is larger. Formally, an increase in the counterfeit activity implies that the marginal value of signalling $\left(\beta_{A}^{i}\right)^{-1}$ of each authentic product $i$ will be increased by the same factor: consumption of an authentic good is more valuable in terms of signalling status in a market with higher consumption of counterfeits.

Second, let's focus on what happens to the profits of a luxury brand as consumers can establish a clear image of status by consuming it. The counterfeiter activity leads to higher profits earned by the authentic brand because a strong status signal attached to a product increases the willingness to pay of the consumer.

\footnotetext{
${ }^{19}$ Note that if the production cost of all the products are identical, then $\frac{c_{A}^{k+1}}{c_{A}^{k}}=1$, which is a special case under Case 2.
} 
To see the impact of market characteristics on price, sales, and profit of the authentic brands clearly, let's rewrite the marginal value from signalling of the $k^{\text {th }}$ product as a function of the market share of counterfeits $(1-\rho)$, and the difference in average quality of the luxury and the counterfeit goods $\left(\Delta \mu:=\mu_{A}-\mu_{C}\right)$ :

$$
\left(\beta_{A}^{k}\right)^{-1}=(1-\rho) \Delta \mu \frac{\sigma^{2}(k-1)}{\sigma_{0}^{2}} \cdot \frac{\sigma^{2}(k-1)}{\sigma^{2}(k-1)+\left(\sigma^{k}\right)^{2}}
$$

The expression delivers the insight that the marginal signalling value is higher when the market share of the counterfeits is higher. This is because a consumer will stand out more with her visible consumption when everyone else is consuming the lower quality counterfeit goods. In Figure 2, we present results from a numerical simulation ${ }^{20}$ which demonstrates how a change in the market share of the counterfeits $(1-\rho)$ influences the optimal length of the portfolio and the price of the core product.

The simulation points to two clear patterns: an increasing share of the counterfeiter pushes brands to extend their product line and the core product has more signalling value and thus higher price. ${ }^{21}$ It also implies that the optimal product line should remain the same if the market share of the counterfeits is within a certain range. As the prices of the goods in the portfolio increase, this pushes the demand downward, resulting in the inverse U-shaped relationship for the total revenue of the brand. Therefore an increasing proportion of counterfeit activity, until a threshold, can make consumption of the authentic goods more valuable from the perspective of signalling status and drive prices and revenue higher. In a market congested with counterfeit activity, however, the prices are so high that only a very small segment of consumers can afford them, and revenues are declining again.

Proposition 3. (Counterfeiter Impact on Brand Profit) Under the optimal product line decision, when the size of the low-end consumer segment is moderate, the luxury brand's profit increases in the market share of the counterfeiter. In other words, luxury brands can benefit from an increase in the counterfeit activity.

Proposition 3 specifically focuses on the profit as an outcome and demonstrates a key takeaway from our study: luxury brands can benefit from an increased counterfeit activity. As the market share of the counterfeits increases, the signalling value of the luxury products increases, which in turn can increase the profitability of the luxury brands. Notice, however, that the positive

\footnotetext{
${ }^{20}$ In this exercise, we set $\Delta \mu=30, \sigma_{1} / \sigma_{0}=1$ and $c_{A}^{k}=1, \forall 1 \leq k \leq n$.

${ }^{21}$ Since the change in $\rho$ is continuous whereas the change in product line length is discrete (it can only take integer numbers), the relationship in the top graph exhibits a saw-tooth shape.
} 
Figure 2: Luxury Brand Product Line and Total Revenue vs. Market Share of the Counterfeit
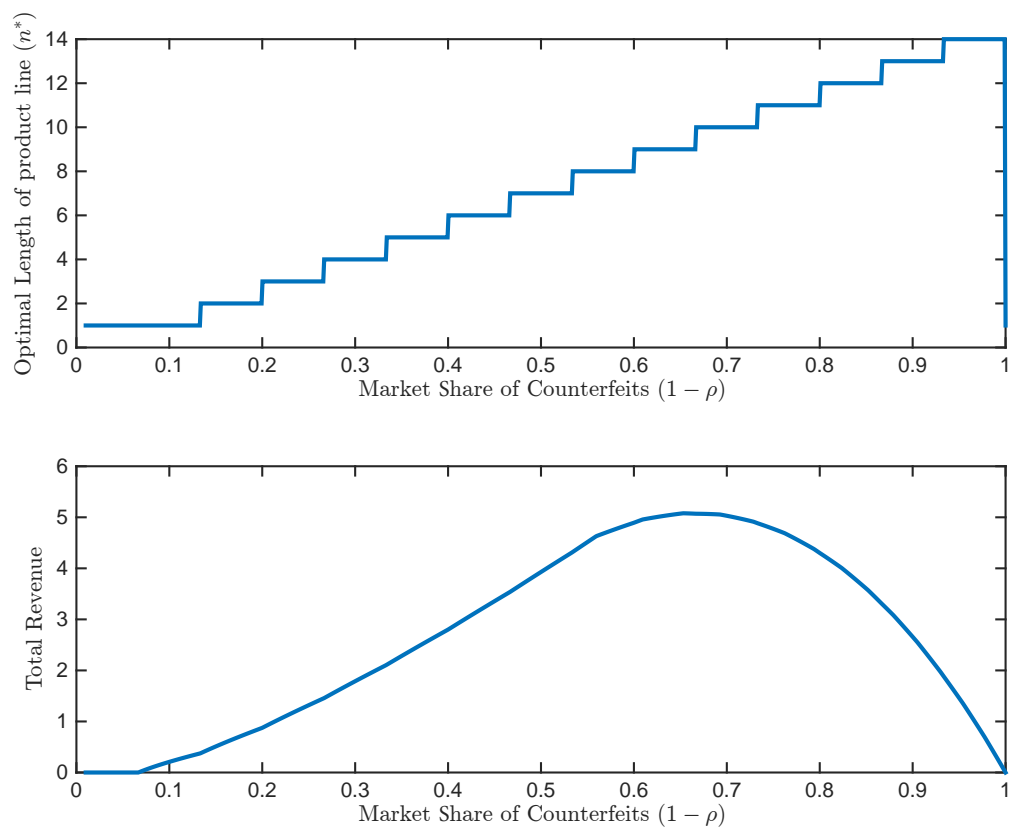

impact on profits is conditional on the size of the low-end segment, and the increase only holds when the segment is not too large. For Proposition 3 to hold, there must exist a market for the counterfeiter. ${ }^{22}$ The magnitude of the increase in profit depends on how fast the market for highend consumers $\left(1-\alpha^{*}\right)$ shrinks vs. how fast the prior $\mu_{0}$ decreases as $\alpha^{*}$ is larger. Moreover, the greater the difference in quality $(\Delta \mu)$ between the luxury brand and the counterfeiter is, the faster the signalling value of the authentic product increases when the counterfeit market expands, feeding into a greater increase in the profit of luxury brand.

Proposition 4. (Counterfeiter Impact on Brand Revenue \& Pricing) As the market share of the counterfeiter increases, for the luxury brand

(i) total revenue exhibits an inverse U-shape (increases and then decreases),

(ii) keeping the product line fixed, the optimal price of each product is monotonically increasing, and (iii) the difference between the optimal prices of the core and the lowest ranked product widens.

We find in Proposition 4 parts (i) and (ii) that total revenue exhibits an inverse U-curve while the price of the core product always benefits from the presence of a higher counterfeit activity. There is a pricing advantage in a market with higher counterfeiting activity because the consumption of each authentic product emits a more credible signal. Figure 3 demonstrates how the profit of the

\footnotetext{
${ }^{22}$ We show in the Appendix that a sufficient condition for the proposition to hold is $\alpha^{*} \leq \frac{2}{3}$. Within this range, high-end consumers do not crowd out the market.
} 

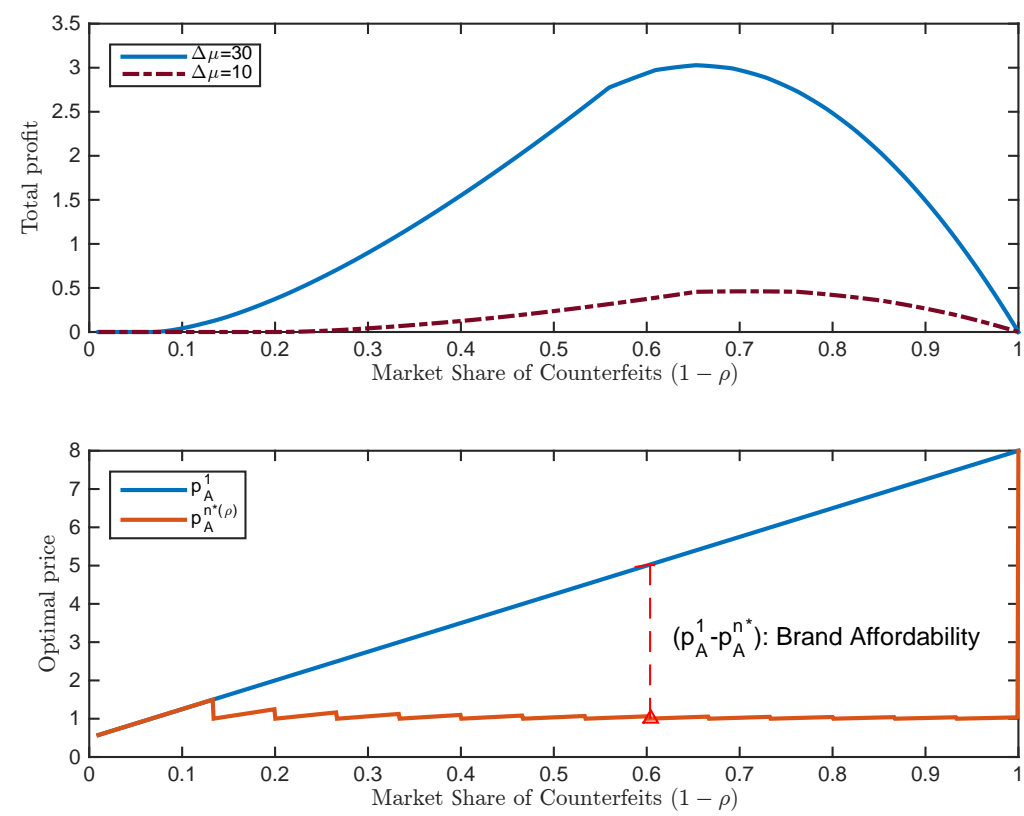

Figure 3: Total Profit and Prices of the Luxury Brand vs. Counterfeit Market Share

luxury brand moves as the market share of the counterfeiter moves and how quality premium $(\Delta \mu)$ affects the scale of this trend.

Proposition 4 also points to a counter-intuitive finding related to the sales and price management of a luxury brand. Generally, higher sales leads to higher prices. That is, it is easy for a luxury brand manager to increase the prices of her products if the sales numbers are improving. According to the proposition, keeping the product line length fixed ${ }^{23}$, it is optimal for the luxury brand to increase the prices of its old products while extending its product line even if the sales are in decline. This is because when the counterfeiter captures a larger fraction of the market, by differentiating its loyal customers from the rest of the population, the luxury brand charges a higher price and extracts more surplus. Moreover, since the marginal signalling value and its marginal increment across products are proportional to the market share of the counterfeiter, the luxury brand can stretch the differences between two consecutively ranked products across the products in a portfolio.

The strategy of offering a range of luxury products can bring to mind the recent trend of affordable luxury - brands offering luxury products at lower prices compared to their core product. We consider the findings here related to this trend as well. Proposition 4 part (iii) suggests that in a market where counterfeiting activity is higher, luxury brands are more likely to be involved in an affordable luxury strategy. This trend reveals a combined effort in product line extension: the luxury

\footnotetext{
${ }^{23}$ When the product line length is not fixed and expanding, the new products added to the line may have lower prices than the lowest priced product before the expansion.
} 
brand charges a higher price of its core product to extract more surplus while offering new products at a lower price that appeals to its most status-conscious consumers. The key logic for the affordable luxury movement according to our framework, however, is not to expand the market to include new, low-income or price sensitive consumers by offering products at a lower price. The movement can have significant benefits for increasing the consumption of the status-conscious consumers. Luxury brands in fact offer a range of goods which are ranked in status signals and prices so that consumers who want to signal status can buy multiple items. Put differently, goods are priced to match their marginally declining status signals.

Proposition 5. (Optimality of Product Line Expansion) For a luxury brand, it is not always optimal to expand the product line. In particular, if the size of the low-end segment is small $\left(\alpha^{*} \in\right.$ $\left.\left[0, \min _{i \leq n}\left\{\frac{1}{2}\left(c_{A}^{i} \beta_{A}^{i}+1\right)\right\}\right]\right)$, it is optimal to offer multiple products, but the optimal length of the product line is independent of the change in $\alpha^{*}$. If the high-end segment is compressed due to the expansion of the counterfeiter $\left(\alpha^{*} \in\left[\max _{i \leq n}\left\{\frac{1}{2}\left(c_{A}^{i} \beta_{A}^{i}+1\right)\right\}, 1\right]\right)$, the luxury brand should extend its product line in response to the increasing share of counterfeiter.

Proposition 5 shows that it is not always optimal to expand the product line for a luxury brand in response to the counterfeit activity. In particular, when the share of the counterfeiter market increases but is not large enough to tamper with the sales of the luxury brand, it does not affect the optimal product line decision. However, when $\alpha^{*}$ exceeds a threshold value $\left(\max _{i \leq n}\left\{\frac{1}{2}\left(c_{A}^{i} \beta_{A}^{i}+1\right)\right\}\right)$, it is still optimal for the luxury brand to offer a portfolio of products but such that it appeals only to a narrower portion of the high-end consumer segment. In this environment, the best response for the luxury brand is to extend its product line by taking advantage of the increasing willingness to pay of their most loyal customers.

Proposition 6. (Luxury Brand Quality Premium) Ceteris paribus, if the quality premium shrinks,

(i) the demand, revenue, profit, and prices of the luxury brand decline, and

(ii) the optimal product line length decreases.

The proposition explains the role of keeping a quality premium for the luxury brand. In order to maintain a pricing and revenue advantage, luxury brands must ensure that they invest into the quality of their brand. Put differently, in a market with highly sophisticated counterfeiters, the luxury brand's advantage is eroding. In sum, what a luxury brand needs to do to compete with counterfeits is to worry less about their market share. A moderately large market share of the counterfeiter may empower status goods by increasing their signal value. But if the gap between 
the quality produced by the luxury brand and the counterfeiter closes, this will harm the luxury brand. The recommendation for luxury brands is to ensure counterfeiters do not access the same quality of production resources as they do, and to open the gap in quality whenever possible.

\section{Extensions}

In this section, we extend the discussion in the main part of the paper to consider changes in the market conditions which may influence the strategy of the luxury brand.

\subsection{Luxury Brands with Multiple Core Products (Homogeneous Status Signals)}

Our first extension focuses on the manufacturing ability of a brand. In particular, the portfolio of products offered by the luxury brand may not vary significantly in their signalling value due to exogenous reasons such as limited recognition of the brand, the inability to establish a core product, or the lack of technology to sufficiently differentiate products in their signalling value. For instance, if a brand offers only luxury handbags, the products may show sufficient similarity and may look identical in their signals. Notice that when products in the line have similar signalling values, a brand has multiple core products, but lacks a "true" core.

Moving away from our benchmark construction, we now consider a brand which offers products that are identical in the precision of their status signals, $\sigma^{i} \equiv \sigma \forall i=1, \ldots, k$. Put differently, we are considering a brand which operates without a true core. The products are not ranked along the product line. If the consumption of these products yields a similar signal, then for a consumer there are no incentives to pay more for any one of them. If the portfolio of products are offered at an identical price, denoted as $p_{A}$, the demand for the $k^{\text {th }}$ product becomes

$$
D\left(p_{A}, k\right)=1-\max \left\{\alpha^{*}, F\left(\beta_{A}^{k} p_{A}\right)\right\}
$$

And the profit function for outlet $s$ offering $n$ products can be simply represented with the marginal profit multiplied by the total demand for the line:

$$
\Pi(A, n)=\left(p_{A}-c_{A}\right) \sum_{k=1}^{n}\left(1-\max \left\{\alpha^{*}, F\left(\beta_{A}^{k} p_{A}\right)\right\}\right)
$$

When the low-end segment size $\alpha^{*}$ is small enough to satisfy $\frac{\beta_{A}^{1}}{2}\left(\frac{n}{\sum_{k=1}^{n} \beta_{A}^{k}}+c_{A}\right) \geq \alpha^{*} \Longleftrightarrow p_{A} \beta_{A}^{1} \geq$ 
$\alpha^{*}$, there exists a unique interior solution. The first order conditions with respect to price are

$$
\sum_{k=1}^{n}\left(1-F\left(\beta_{A}^{k} p_{A}\right)\right)-\left(p_{A}-c_{A}\right) \sum_{k=1}^{n} \beta_{A}^{k} f\left(\beta_{A}^{k} p_{A}\right)=0
$$

When $\alpha$ is uniformly distributed $(f(\cdot)=1$ ), we prove in the Appendix that the price function is given by

$$
p_{A}^{*}= \begin{cases}\frac{1}{2}\left(\frac{n}{\sum_{k=1}^{n} \beta_{A}^{k}}+c_{A}\right) & \alpha^{*} \in\left(0, \bar{\alpha}^{0}\right] \\ \frac{\alpha^{*}}{\beta_{A}^{m}} & \alpha^{*} \in\left(\bar{\alpha}^{m-1}, \bar{\alpha}^{m}\right] \\ \frac{\alpha^{*}}{\beta_{A}^{n}} & \alpha^{*} \in\left(\bar{\alpha}^{n-1}, 1\right]\end{cases}
$$

where $\bar{\alpha}^{m} \equiv \frac{\frac{n}{\sum_{k=m+1}^{n} \beta_{A}^{k}}+c_{A}}{\sum_{k=m+1}^{n} \beta_{A}^{k}+\frac{2}{\beta_{A}^{m}}}, \forall 0 \leq m \leq n-1$.

Notice that with homogeneous signals and prices, compared to the benchmark analysis, the length of the product line (directly) influences the prices of the products, aside from their marginal signal value and costs. The key difference is in how the prices change as the brand extends its product line. In the benchmark model, we found that as long as a luxury brand can extend its product line by credibly differentiating the signals of its products, extending the product line will result in also higher prices. In contrast, a luxury brand which fails to differentiate products sufficiently in signalling status loses its competitive advantage in pricing. In this case, extending the product line results in the loss of ability to charge higher prices. As the product line increases, the price of goods decreases. Because these goods are similar to each other in their desirability, adding more of them to a product line does not yield additional demand unless they are offered at a lower price. As a result, the optimal portfolio size of luxury brands will be much smaller for those who fail to differentiate products in their signalling value than in our benchmark case.

To see this result, recall from Lemma 1 that the signal values of products $\left(\beta_{A}^{k}\right)^{-1}$ are decreasing in their ranking order $k$ (or, equivalently, $\beta_{A}^{k}$ increasing in $k$ ), therefore the average value of an increasing sequence of $n$ elements $\left(\frac{\sum_{k=1}^{n} \beta_{A}^{k}}{n}\right)$ should also increase with respect to $n$. On the other hand, as $n$ increases each interval $\left(\bar{\alpha}^{m-1}, \bar{\alpha}^{m}\right]$ has to be shorter and thus $\bar{\alpha}^{m}$ decreases in $n$. It implies that fixing $\alpha^{*}$, the prices will drop as the luxury brand extends its product line. Formally, the profit function with $n$ products under optimal pricing is given by 


$$
\Pi\left(p_{A}^{*}, n\right)= \begin{cases}\frac{1}{\sum_{k=1}^{n} \beta_{A}^{k}}\left(\frac{n}{2}-\frac{c_{A} \sum_{k=1}^{n} \beta_{A}^{k}}{2}\right)^{2} & \alpha^{*} \in\left(0, \bar{\alpha}^{0}\right] \\ \left(\frac{\alpha^{*}}{\beta_{A}^{m}}-c_{A}\right)\left[n-\alpha^{*}\left(m+\sum_{k=m+1}^{n} \frac{\beta_{A}^{k}}{\beta_{A}^{m}}\right)\right] & \alpha^{*} \in\left(\bar{\alpha}^{m-1}, \bar{\alpha}^{m}\right], \forall 1 \leq m \leq n-1 \\ \left(\frac{\alpha^{*}}{\beta_{A}^{n}}-c_{A}\right) n\left[1-\alpha^{*}\right] & \alpha^{*} \in\left(\bar{\alpha}^{n-1}, 1\right]\end{cases}
$$

How does counterfeiting activity influence brands which fail to differentiate its product offerings in their status signals? We present in Figure 4 how the influence of counterfeits now changes the strategy of a brand ${ }^{24}$. We highlight one difference pertaining to the product line decision. Increasing activity of the counterfeits should not change the optimal product line length because although higher counterfeit activity increases the signal value of each product, since all products carry identical signals, they are competing with each other and a longer product line is offered at a lower price. Subsequently, there is only one product line length which maximizes the profit. Comparing Figures 2 and 4 which are obtained under the same parameter values, we note that a brand without a true core (i.e., with multiple cores) chooses to go for a significantly shorter product line and still obtains lower total sales and profit.
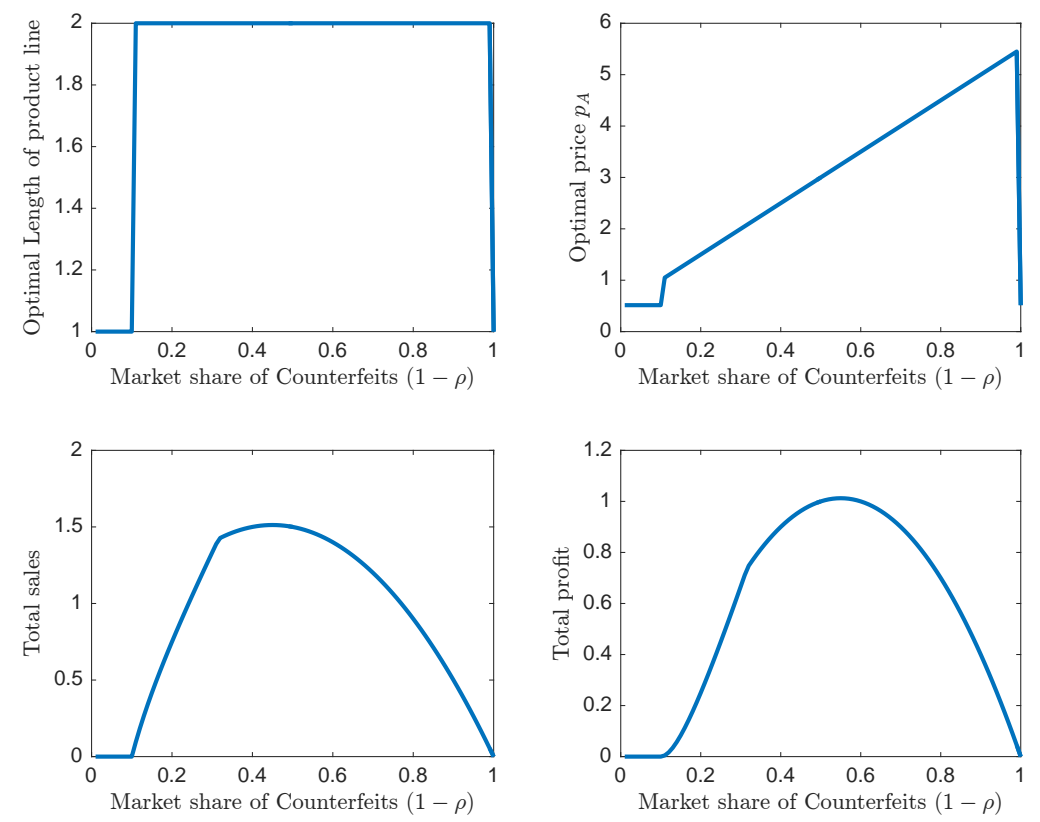

Figure 4: Luxury Brand Strategy and Performance vs. Market Share of Counterfeiter (Homogeneous product line)

\footnotetext{
${ }^{24}$ The parameter values remain the same as in our benchmark: $\Delta \mu=30, \sigma_{1} / \sigma_{0}=1$ and $c_{A}=1$.
} 
Proposition 7. (Importance of Differentiation in Product Line) If the luxury brand fails to differentiate its products sufficiently in status signals, extending the product line fails to be a profit lever when the share of counterfeiters increases.

When the luxury brand cannot differentiate its products sufficiently in their status signals (and therefore in pricing), extending the product line is less likely to be a profitable strategy. The luxury brand's profit will fall under single pricing if the firm extends its product line, which follows from

the fact that the marginal signalling value $\left(\beta_{A}^{k}\right)^{-1}$ decreases as each consumer buys more of the same products, and as a result their willingness to pay falls on average. In summary, not being able to differentiate goods in signalling (or, failing to price goods differently even if their signals were different) limits the profits that the luxury brand can extract from the consumers via expanding its product line.

\subsection{Endogenous Formation of Low-end and High-end Segments}

In the benchmark model, we assume that there are two exogenously defined consumer segments. These consumer segments vary in their reasons for purchasing goods, one focusing on status and the other focusing on the consumption value of goods. We now test the robustness of the results endogenizing the distinction between the two segments, assuming that consumers' utility function on the entire support of $\alpha \in[0,1]$ is given by:

$$
1_{\{k \geq 1\}} \cdot\left[\alpha \mu_{0}+\sum_{i=1}^{k}\left(\alpha\left(\beta_{s}^{i}\right)^{-1}-p_{s}^{i}\right)\right]
$$

where $\left(\beta_{s}^{i}\right)^{-1} \equiv E\left(\mu_{1} \mid k, s\right)-E\left(\mu_{1} \mid k-1, s\right)$ for all $k \leq n$.

It is easy to show that our benchmark model for the high-end consumers is a specific example of the generalized version proposed in this section. Conditional on buying, the utility function of the consumer remains identical to the one in the benchmark model, except that the utility of not buying $\left(E\left(\mu_{1} \mid 0, s\right)\right)$ is set to zero instead of $\mu_{0}$ in the extended model.

Note that consumers' utility consists of two sources: (1) consumption value, which is endogenously determined by market average quality $\left(\mu_{0}\right)$ and $(2)$ status-signalling value $\left(\sum_{i=1}^{k}\left(\beta_{s}^{i}\right)^{-1}\right)$, which is negatively correlated with $\mu_{0}$. Only signalling value is accumulated on buying multiple products, while consumption value remains unchanged once a consumer makes his/her first purchase. Recall that marginal value of signalling from buying a counterfeit is negative since 


$$
\begin{aligned}
{\left[\beta_{C}^{2}\right]^{-1} } & =E\left(\mu_{1} \mid 2, C\right)-E\left(\mu_{1} \mid 1, C\right) \\
& =\left(\mu_{C}-\mu_{0}\right) \frac{\sigma^{2}(1)}{\sigma_{0}^{2}} \cdot \frac{\sigma^{2}(1)}{\sigma^{2}(1)+\left(\sigma^{1}\right)^{2}} \\
& <0
\end{aligned}
$$

where $\sigma^{2}(1)=\left[\frac{1}{\sigma_{0}^{2}}+\frac{1}{\left(\sigma^{1}\right)^{2}}\right]^{-1}$. So low-end consumers obtain a positive utility from purchasing a counterfeit good, but have no incentive to buy a second counterfeit item because the marginal value of signalling is negative. They do not gain additional consumption value from buying extra units. So counterfeiters only produce a single product (an imitation of the authentic core). Hence consumers with status-consciousness at the cut-off $\alpha^{*}$ must be indifferent between buying one counterfeit and one core authentic product, $\alpha^{*}$ should solve

$$
\alpha^{*} E\left(\mu_{1} \mid 1, A\right)-p_{A}^{1}=\alpha^{*} E\left(\mu_{1} \mid 1, C\right)-p_{C},
$$

which yields

$$
\alpha^{*}=\frac{p_{A}^{1}-p_{C}}{E\left(\mu_{1} \mid 1, A\right)-E\left(\mu_{1} \mid 1, C\right)}=\frac{p_{A}^{1}-p_{C}}{\mu_{A}-\mu_{C}} \cdot \frac{\sigma_{0}^{2}+\left(\sigma^{1}\right)^{2}}{\sigma_{0}^{2}} .
$$

Among low-end consumers, only those with $\alpha \geq \underline{\alpha}$ will buy any products given price $p_{C}$, where we define $\underline{\alpha}$ as the status sensitivity of the marginal consumer who is indifferent between buying the counterfeit good and nothing. For this consumer, the following constraint holds:

$$
\underline{\alpha}\left[E\left(\mu_{1} \mid 1, C\right)-E\left(\mu_{1} \mid 0, C\right)\right]-p_{C}=0
$$

Recall that $E\left(\mu_{1} \mid 0, C\right)=0$. So substituting into the above expression yields the status sensitivity of this marginal consumer:

$$
\underline{\alpha}=\frac{p_{C}}{E\left(\mu_{1} \mid C\right)}=\frac{p_{C}}{\frac{\mu_{0}}{\sigma_{0}^{2}}+\frac{\mu_{C}}{\sigma_{1}^{2}}} \cdot\left[\frac{1}{\sigma_{0}^{2}}+\frac{1}{\sigma_{1}^{2}}\right]
$$

In this scenario, a two-segment market structure $\left(\left[\underline{\alpha}, \alpha^{*}\right] \cup\left[\alpha^{*}, 1\right]\right)$ is endogenously defined by and tied to the cut-off threshold $\alpha^{*}$ at which a consumer is indifferent between buying authentic brands and counterfeits. Recall that in the benchmark, we had exogenously set $\rho=1-\alpha^{*}$, which is a simplified version of the endogenous case we discuss in this section. Thus the segmentation provided in the benchmark model can be justified with an endogenous segmentation model. 


\section{Discussion, Conclusions and Insights}

Luxury goods industry around the world is growing and is estimated to reach a total revenue size of $\$ 280$ billion by 2020 (Bain and Company, 2013). The growing demand for luxury goods also feeds the demand for their lower priced, lower quality imitations, resulting in an increasingly more active counterfeit industry. Brands are looking for ways to combat the competition they face from the counterfeiting activity. In this study, we investigate how the brands seen as status symbols can use portfolio expansion strategies to combat counterfeits and enhance the value of their brands. Anecdotal observations support the notion that luxury brands have been adding lower priced goods to their portfolios. Ferrari, in addition to selling cars, offers t-shirts, key chains, cell phone covers. Hermés offers, in addition to clothing and handbags, stationary and fragrances. All of these goods have different levels of visibility and price point. Related to this, some luxury brands also have been involved in an affordable luxury movement.

At first glance, the objective of luxury brands expanding their product lines by offering lower visibility and lower priced additions of their goods seem to be an attempt to reach the lower income consumer groups. Increasing the overall population of consumers who are interested in buying these goods seems like the main goal of adopting this strategy. It is possible that this is one objective, but our paper lays out another strategic benefit. We argue that many luxury brands are consumed by status-conscious consumers who are interested in strengthening their image by increasing their overall consumption level. Status, however, is in the eye of others. Additional consumption of luxury items strengthen one's image, but only at a weaker, marginally declining fashion. So it is only rational for these consumers to buy additional products of lesser status signals and pay less for them to improve their image (rather than buying goods of similar status signals and price levels). We posit that the expansion of luxury product portfolios serve this latter goal of providing the high-end, status-conscious consumers with additional products to strengthen their image rather than expanding to consumers with little or low status-consciousness. Moreover, we show that for brands with capabilities of differentiating products and their status signals, it is in their best interest to expand the product line.

Unlike regular goods, consuming multiple goods from a line of products can increase the credi-

bility of authenticity, when this consumption can be observed by others. We find that the pricing strategies of the core and the peripheral products depend on how fast the signalling value changes as opposed to the marginal cost of production. Compared to the counterfeits, luxury brands maintain a pricing advantage such that when they offer a portfolio of products, the prices decline at a lower rate moving from the core product to the peripheral products. We show that in this environment, presence of counterfeiters does not create disadvantages in pricing. Similarly, when the market for 
low-end consumers is small, a larger market share of counterfeiters can increase the sales and profits of a brand.

When do counterfeiters hurt a brand? Our findings point to three cases. First, in a market where a significant majority of the consumers are not interested in signalling status, increasing counterfeit shares will increase prices, but the demand will decline faster such that profits will suffer altogether. Second, if the counterfeiters are closing the quality gap with the authentic brand, it becomes a threat for the luxury brand. It is the quality rather than the quantity of the counterfeiting activity, which can hurt these brands. Finally, as we show in Section 4, if a luxury brand is unable to offer goods which are sufficiently differentiated as status signals, these goods cannot be priced heterogeneously and expanding product lines only aggravate their competition. In this market, again, a higher share of counterfeits can make the products more visible and valuable for consumption, but luxury brands cannot fully take advantage of the product line expansion and profit maximization outcomes.

\section{Insights for Luxury Brand Managers}

Counterfeiting activity is concerning to many brand managers because it is believed to negatively influence sales, profits, value of a brand and the investment into development of new goods. Our findings demonstrate that these concerns may be alleviated to some degree. We offer the following key takeaways for the luxury brand managers.

1. Status signalling properties of luxury brands and conspicuous goods lend themselves naturally to product line expansion. A unique property of luxury brands is the desire of their target consumers to convince others of the authenticity of their investment. Luxury brands, or brands of visible consumption, unlike brands which produce ordinary goods, can benefit from expanding their product line. Existence of outside options, even the market share of competitive counterfeiters, can increase the desire to differentiate for those who care highly about their status. In order to make it costlier on others to imitate status, consumers will purchase additional units.

2. To encourage consumers to strengthen status image in a market with counterfeits, luxury brands should offer peripheral products in addition to their core product. What is important is that these products should be sufficiently differentiated. These additional goods should not be of the same status level as the core (or higher ranked) products, and they should be priced at a lower level, matching their signal precision. This implies that when necessary the brand manager should not be afraid of offering a t-shirt when producing cars. In line with the way other consumers learn about one's status, availability of peripheral, marginally 
declining (in status), lower priced goods will motivate higher end consumers to buy more and improve their image. These goods, unlike what the intuition may suggest, appeal to the the high-end status-conscious consumers rather than the low-end ones. Put differently, with product line extension, luxury brands' profit gains come from the intensive rather than the extensive margin: from existing consumers increasing spending, rather than the gains from new consumers.

3. When it comes to the competition with counterfeiters, mind quality over quantity. A higher share of counterfeiters implies that the average good in the market is more likely to be a counterfeit. Since a market with heavy counterfeit activity will lead to lower average beliefs about the prior quality, the signal delivered by each good make a larger difference in consumers' updating their beliefs about the authenticity of a product with luxury brand quality. The goods of the luxury brand become easier to distinguish among many low quality fakes. In this market, high-end consumers have higher incentives and more willingness to pay for a good that can easily establish their status. Thus higher counterfeit activity implies higher prices, and this can also positively influence the sales and profits for a luxury brand. Thus, although there can be many negatives associated with the presence of counterfeits, one advantage can be the increased value of an authentic good consumption in status perceptions of the consumers.

4. The one case when the battle against the counterfeiters is lost is when the luxury brand cannot maintain a quality premium over the counterfeiters. If the counterfeiters increase their sophistication and become visibly indistinguishable in their quality, or if the luxury brands fail to invest into quality production, it is expected that this will hurt the brands. A declining quality premium over the counterfeiters will result in a decline in prices and profits for the luxury brands.

5. Managers of luxury brands have a pricing advantage over the managers of counterfeiters. The target consumer segment of the authentic brand will be more likely to buy an additional product at a price close to the price of the core product, whereas counterfeiters have to drop prices dramatically for lower ranked products. What managers need to pay attention is, when they expand their product line, the pricing of the products in the line should follow the value of the products in terms of their status signalling value. Allowing products to have varying associations with status can naturally lead to an ordering, and when it does, pricing order should follow. Otherwise, some of the products in the product line will not find appropriate demand, resulting in inefficient line expansion. 


\section{Insights for Policy Makers}

Luxury brands see higher levels of threat from counterfeiters and enforcement forces operate globally to seek for ways to combat this activity. Most of such activity is taken under a legal umbrella - police enforcement over the counterfeiters, copyright lawsuits, etc. Unfortunately, these strategies alone do not help luxury brands, because they are expensive and they require round-the-clock monitoring. Our suggestion is that policy makers should reconsider their gains from the intensive and expensive fight with lower quality imitations of the luxury goods but rather focus their effort on preventing the closure of the quality gap. The key in the battle for counterfeits should not be the day to night fight with the street sellers, or enforcement on low quality imitators. The real battle is with the sophistication of production by counterfeits. How could policy makers support luxury brands in their fight to maintain a quality premium? Enforcement should be on the high quality manufacturing facilities which allocate production resources to counterfeiters. Policy makers and regulators should aim for the monitoring of these facilities first to increase enforcement efficiency. Other measures of battling counterfeits include preventing or auditing deceptive advertising by counterfeits, quality (authenticity) certificates, and production details which cannot be replicated by the counterfeiters. From the policy maker's perspective, whether brands can take advantage of their core consumers' visible consumption desire and the willingness to pay for it effectively should be the main concerns for protecting the value of these brands. Firms can benefit from strategies that are unique to the nature of their brands and the needs of their target consumers.

Counterfeiting is a longstanding problem for policy makers because of the concerns that it will impact innovation activity and consumer welfare negatively and will increase the level of crime in a society. While our study does not focus particularly on the crime or innovation outcomes, it demonstrates that counterfeiters can motivate brands to extend product lines. Under the assumption that products are differentiated, our findings suggest that design and creation of new products do not necessarily decrease in the counterfeit activity. Moreover, when these products offer higher status signalling benefits, they can increase consumer welfare. Product line expansion not only introduces

more options for the status-conscious consumers to stand out and enjoy a greater consumer surplus, but it also offers incentives for luxury brands to improve their brand affordability.

\section{Limitations}

We argue that an increased share of counterfeiting activity may increase the profits of the luxury brand. It is important to recognize that the same results will not apply to goods which are not consumed for status. The desire to signal status via consuming multiple goods differentiated in signals and the aggregation of signals to update beliefs about one's status are key to our findings, 
and it is the underlying reason behind brand's expansion of lines. One could not make the same conclusions about the competition between two firms producing goods of regular consumption with no desire to signal status.

Moreover, it should not be concluded that the fight against counterfeiters should be marginalized. In many countries, it is still important that a continuous investment into the battle with counterfeiters is made to ensure a quality premium can be maintained between the luxury brands and counterfeiters. That being said, our study and several others before us (Qian, 2014a; Romani et al., 2012) conclude that the relationship between counterfeiters and luxury brands is not a monotonic, one-sided relationship with only one party benefiting from the presence of others. While counterfeiters benefit from luxury brands, the opposite may also hold. It is necessary to test when and under what conditions these claims may empirically hold. We leave these ideas for other scholars to put to test.

\section{References}

Amaldoss, W. and Jain, S. (2005a). Conspicuous consumption and sophisticated thinking. Management Science, 51(10):1449-1466.

Amaldoss, W. and Jain, S. (2005b). Pricing of conspicuous goods: A competitive analysis of social effects. Journal of Marketing Research, 42(1):30-42.

Amaldoss, W. and Jain, S. (2015). Branding conspicuous goods: An analysis of the effects of social influence and competition. Management Science, 61(9):2064-2079.

Anderson, C., John, O. P., Keltner, D., and Kring, A. M. (2001). Who attains social status? effects of personality and physical attractiveness in social groups. Journal of Personality and Social Psychology, 81(1):116-132.

Bagwell, L. S., Bernheim, B. D., et al. (1996). Veblen effects in a theory of conspicuous consumption. American Economic Review, 86(3):349-73.

Bai, J. and Waldfogel, J. (2012). Movie piracy and sales displacement in two samples of chinese consumers. Information Economics and Policy, 24(3):187-196.

Balachander, S. and Stock, A. (2009). Limited edition products: When and when not to offer them. Marketing Science, 28(2):336-355.

Bellezza, S., Gino, F., and Keinan, A. (2014). The red sneakers effect: Inferring status and competence from signals of nonconformity. Journal of Consumer Research, 41(1):35-54. 
Bellezza, S. and Keinan, A. (2014). Brand tourists: How non-core users enhance the brand image by eliciting pride. Journal of Consumer Research, 41(2):397-417.

Berger, J. A., Ho, B., and Joshi, Y. V. (2011). Identity signaling with social capital: a model of symbolic consumption. Johnson School Research Paper Series, No. 27-2011.

Besley, T. and Ghatak, M. (2008). Status incentives. The American Economic Review, 98(2):206211.

Bhattacharya, H. and Dugar, S. (2014). Partnership formation: The role of social status. Management Science, 60(5):1130-1147.

Campbell, R. T. and Henretta, J. C. (1980). Status claims and status attainment: The determinants of financial well-being. American Journal of Sociology, 86(3):618-629.

Chaudhuri, H. R. and Majumdar, S. (2006). Of diamonds and desires: Understanding conspicuous consumption from a contemporary marketing perspective. Academy of Marketing Science Review, 2006:1-18.

D'Arpizio, C., Levato, F., Zito, D., and de Montgolfier, J. (2015). A time to act: How luxury brands can rebuild to win. Bain 63 Co Luxury Goods Worldwide Market Study.

Dauriz, L. and Tochtermann, T. (2013). Luxury lifestyle: Beyond the buzzwords. McKinsey Report.

Draganska, M. and Jain, D. C. (2006). Consumer preferences and product-line pricing strategies: An empirical analysis. Marketing Science, 25(2):164-174.

Dubois, D., Rucker, D. D., and Galinsky, A. D. (2012). Super size me: Product size as a signal of status. Journal of Consumer Research, 38(6):1047-1062.

Eisend, M. and Schuchert-Güler, P. (2006). Explaining counterfeit purchases: A review and preview. Academy of Marketing Science Review, 2006(12):1.

Ferraro, R., Kirmani, A., and Matherly, T. (2013). Look at me! Look at me! Conspicuous brand usage, self-brand connection, and dilution. Journal of Marketing Research, 50(4):477-488.

Flynn, F. J. (2003). How much should i give and how often? The effects of generosity and frequency of favor exchange on social status and productivity. Academy of Management Journal, 46(5):539553.

Givon, M., Mahajan, V., and Muller, E. (1995). Software piracy: Estimation of lost sales and the impact on software diffusion. The Journal of Marketing, 59(1):29-37. 
Hamilton, R. and Chernev, A. (2010). The impact of product line extensions and consumer goals on the formation of price image. Journal of Marketing Research, 47(1):51-62.

Han, Y. J., Nunes, J. C., and Drèze, X. (2010). Signaling status with luxury goods: The role of brand prominence. Journal of Marketing, 74(4):15-30.

Hardie, B. G., Lodish, L. M., Kilmer, J. V., Beatty, D. R., Farris, P. W., Biel, A. L., Wicke, L. S., Balson, J. B., and Aaker, D. A. (1994). The logic of product-line extensions. Harvard Business Review, 72(6):53-62.

Horsky, D. and Nelson, P. (1992). New brand positioning and pricing in an oligopolistic market. Marketing Science, 11(2):133-153.

Jain, S. (2012). Marketing of vice goods: A strategic analysis of the package size decision. Marketing Science, 31(1):36-51.

Joshi, Y. V., Reibstein, D., and Zhang, Z. J. (2016). Turf wars: Product line strategies in competitive markets. Marketing Science, 35(1):128-141.

Kuksov, D. and Wang, K. (2013). A model of the "it" products in fashion. Marketing Science, $32(1): 51-69$.

Kuksov, D. and Xie, Y. (2012). Competition in a status goods market. Journal of Marketing Research, 49(5):609-623.

Leibenstein, H. (1950). Bandwagon, snob, and veblen effects in the theory of consumers' demand. The Quarterly Journal of Economics, 64(2):183-207.

Lin, N. (1999). Social networks and status attainment. Annual Review of Sociology, 25(1):467-487.

Ordabayeva, N. and Chandon, P. (2011). Getting ahead of the joneses: When equality increases conspicuous consumption among bottom-tier consumers. Journal of Consumer Research, 38(1):27-41.

Panzar, J. C. and Willig, R. D. (1981). Economies of scope. The American Economic Review, $71(2): 268-272$.

Pesendorfer, W. (1995). Design innovation and fashion cycles. The American Economic Review, $85(4): 771-792$.

Qian, Y. (2008). Impacts of entry by counterfeiters. The Quarterly Journal of Economics, 123(4):1577-1609. 
Qian, Y. (2014a). Brand management and strategies against counterfeits. Journal of Economics $\mathscr{E}$ Management Strategy, 23(2):317-343.

Qian, Y. (2014b). Counterfeiters: Foes or friends? how counterfeits affect sales by product quality tier. Management Science, 60(10):2381-2400.

Randall, T., Ulrich, K., and Reibstein, D. (1998). Brand equity and vertical product line extent. Marketing Science, 17(4):356-379.

Rao, R. S. and Schaefer, R. (2013). Conspicuous consumption and dynamic pricing. Marketing Science, 32(5):786-804.

Romani, S., Gistri, G., and Pace, S. (2012). When counterfeits raise the appeal of luxury brands. Marketing Letters, 23(3):807-824.

Sauder, M., Lynn, F., and Podolny, J. M. (2012). Status: Insights from organizational sociology. Annual Review of Sociology, 38:267-283.

Tereyagoglu, N. and Veeraraghavan, S. (2012). Selling to conspicuous consumers: Pricing, production, and sourcing decisions. Management Science, 58(12):2168-2189.

Torelli, C. J., Leslie, L. M., Stoner, J. L., and Puente, R. (2014). Cultural determinants of status: Implications for workplace evaluations and behaviors. Organizational Behavior and Human Decision Processes, 123(1):34-48.

Van den Bulte, C. and Joshi, Y. V. (2007). New product diffusion with influentials and imitators. Marketing Science, 26(3):400-421.

Veblen, T. (1899). The Theory of Leisure Class. Modern Library, New York, NY.

Waldfogel, J. (2012). Music piracy and its effects on demand, supply, and welfare. Innovation Policy and the Economy, 12(1):91-110.

Wang, Y. and Griskevicius, V. (2014). Conspicuous consumption, relationships, and rivals: Women's luxury products as signals to other women. Journal of Consumer Research, 40(5):834-854.

Webster Jr., F. E. and Wind, Y. (1972). A general model for understanding organizational buying behavior. The Journal of Marketing, 36(2):12-19.

Wilcox, K., Kim, H. M., and Sen, S. (2009). Why do consumers buy counterfeit luxury brands? Journal of Marketing Research, 46(2):247-259. 
Yoganarasimhan, H. (2012). Cloak or flaunt? the fashion dilemma. Marketing Science, 31(1):74-95.

\section{Appendix}

\section{Proof of Lemma 3:}

Note that if $\mu_{s}-\mu_{0} \leq 0$, the first component in Equation 2 becomes non-positive and Equation 3 is never satisfied. Hence consumers never buy such products that lower the expected posterior perceived quality.

\section{Proof of Lemma 4:}

(We drop the subscript $A$ in $\beta$ for simplicity of expressions throughout the proof.)

We first prove that the condition $\frac{\beta_{k}}{\beta_{k-1}} \geq \frac{p_{A}^{k-1}}{p_{A}^{k}}, \forall 1<k \leq n$ is sufficient for consumers to follow the same consumption order as the ranking order of products in the line. Consider the case where a consumer can only buy up to two products. There are only three options for her: to buy only the core product, only the second ranked product, or both of them. Let $u_{a}, u_{b}, u_{c}$ denote the net benefit of options a, b and c. Clearly $u_{a}>u_{b}$ because the signalling precision $\sigma_{k}^{-1}$ is decreasing in $k$ and thus option $\mathrm{b}$ is strictly dominated in this case. If a consumer buys the product that ranked $2^{\text {nd }}$, she should also have bought the core product.

Next, suppose that a consumer endowed with $\alpha$ can buy up to $k$ products and have already bought the $k^{\text {th }}$ product. Since she buys the $k^{\text {th }}$ product, the marginal benefit of buying the product must exceed its price, that is

$$
\frac{\alpha}{\beta_{k}}-p_{A}^{k}>0 \Longleftrightarrow \alpha>\beta_{k} p_{A}^{k}
$$

And if the condition in Lemma 4 holds, that is if $\frac{\beta_{k}}{\beta_{k-1}} \geq \frac{p_{A}^{k-1}}{p_{A}^{k}}$, we can also extend the marginal benefit and price comparison to the $(k-1)^{t h}$ product:

$$
\alpha>\beta_{k} p_{A}^{k} \geq \beta_{k-1} p_{A}^{k-1} \Longrightarrow \frac{\alpha}{\beta_{k-1}}-p_{A}^{k-1}>0
$$

Therefore, she should also be willing to buy the $(k-1)^{t h}$ product. By induction, if the price declines less than the drop in marginal signalling value and a consumer buys the lowest ranked product, she should also buy all the products in the line.

Now we prove by contradiction that the sufficient condition $\frac{\beta_{k}}{\beta_{k-1}} \geq \frac{p_{A}^{k-1}}{p_{A}^{k}}, \forall 1<k \leq n$ for consumers to follow a specific consumption order is also a necessary condition for the luxury brand to achieve optimal pricing. Assume there are $n$ products in the line. Again, first consider the case when $n=2$. Suppose $\frac{\beta_{2}}{\beta_{1}}<\frac{p_{A}^{1}}{p_{A}^{2}}$, then for the marginal consumer with $\alpha_{0}$ who is just indifferent between buying the core product or not, i.e. $\alpha_{0}=\beta_{1} p_{A}^{1}>\beta_{2} p_{A}^{2}$, she should strictly prefer to first buy the second product in the line. But after buying the second product, the marginal return of buying the core product decreases as opposed to the ordered purchase. Let $1 / \beta_{1}^{\prime}$ denote marginal return of buying the second product as first purchase. Clearly 
$1 / \beta_{1}^{\prime}\left(\sigma^{2}\right)<1 / \beta_{1}\left(\sigma^{1}\right)$ given that $\sigma^{2}>\sigma^{1}$. Now the marginal consumer will no longer be willing to buy the core product (since she adopts the reverse consumption order due to the low price of the second product). Similarly, all the consumers with $\alpha$ below her in the high-end segment $\left(\alpha^{*} \leq \alpha<\alpha_{0}\right)$ do not buy the core product. However, the luxury brand can be better off by increasing the price of the second product while

maintaining the price of the first product so that $\frac{\beta_{2}}{\beta_{1}}=\frac{p_{A}^{1}}{p_{A}^{2}}$. In that case, not only does the demand for the core product increases because it also becomes more valuable for consumers who buy it as their first purchase, and all the consumers who are more status conscious than the marginal consumer pay a higher price for the second product.

Similarly, suppose (1) $\frac{\beta_{k}}{\beta_{k-1}} \geq \frac{p_{A}^{k-1}}{p_{A}^{k}}, \forall 1<k \leq n-1$ and (2) $\frac{\beta_{n}}{\beta_{n-1}}<\frac{p_{A}^{n-1}}{p_{A}^{n}}$. For the marginal consumer endowed with $\alpha=\alpha_{0}$ (such that $\alpha_{0}=\beta_{n-1} p_{A}^{n-1}$ ), (1) implies that she should prefer buying all the products ranked above the $(n-1)^{t h}$ while being indifferent about buying the $(n-1)^{t h}$ product. However, from (2) we know that she should strictly prefer to buy the $n^{\text {th }}$ product prior to the $(n-1)^{\text {th }}$ product, because

$$
\alpha_{0}=\beta_{n-1} p_{A}^{n-1}>\beta_{n} p_{A}^{n}
$$

As opposed to $\left\{\beta_{k}\right\}_{k \leq n}$ where consumers follow the ranking order while making a purchase, let $\left\{\beta_{k}^{\prime}\right\}_{k \leq n}$ denote the set of marginal signalling values where consumers follow a consumption order in which the last two purchases are reversed in terms of the ranking order (i.e. the $n^{\text {th }}$ product is consumed before the $\left.(n-1)^{t h}\right)$. Then the marginal signalling value of the second last purchase becomes smaller: $1 / \beta_{n-1}^{\prime}<1 / \beta_{n-1}$, while that of the last purchase becomes larger: $1 / \beta_{n}^{\prime}>1 / \beta_{n}$, because the $n^{\text {th }}$ product sends a less precise thus less valuable signal than the $(n-1)^{t h}$ product. Moreover, we know that $1 / \beta_{n}^{\prime}<1 / \beta_{n-1}$, since the $(n-1)^{t h}$ product becomes less valuable to consumers if they delayed their purchase. Plugging the inequality conditions into (8) yields

$$
\alpha_{0}<\beta_{n}^{\prime} p_{A}^{n-1}
$$

which shows that this marginal consumer with $\alpha=\alpha_{0}$ is not willing to buy the $(n-1)^{\text {th }}$ product after buying the $n^{\text {th }}$ product. The same reasoning applies to all the consumers with $\alpha<\alpha_{0}$. Alternatively, the luxury brand will be better off by increasing $p_{A}^{n}$ while fixing $p_{A}^{n-1}$ so that $\frac{\beta_{n}}{\beta_{n-1}}=\frac{p_{A}^{n-1}}{p_{A}^{n}}$. Then the consumers will again follow the desired consumption order which increases their willingness to pay as well as demand for the $(n-1)^{t h}$ product, in that case the luxury brand will extract more surplus from selling the $n^{\text {th }}$ product to more status conscious consumers at a higher price.

\section{Proof of Proposition 2:}

(We will drop the subscript $A$ in $\beta$ for simplicity of expressions throughout the proof.) We can solve for the optimal price vector $\mathbf{p}$ and Lagrangians $\lambda$ recursively.

If $\lambda_{1}=0$, that is, if the first inequality constraint is not binding, then $p_{A}^{2} \beta_{2}-p_{A}^{1} \beta_{1}>0$. From the first 
two F.O.C.s with respect to prices, we can obtain the prices of the top two ranked products as:

$$
\begin{aligned}
& p_{A}^{1}=\frac{1}{2 \beta_{1}}+\frac{c_{A}^{1}}{2} \\
& p_{A}^{2}=\frac{1}{2 \beta_{2}}+\frac{c_{A}^{2}}{2}-\frac{\lambda_{2}}{2}
\end{aligned}
$$

Substituting into the constraint we obtain:

$$
p_{A}^{2} \beta_{2}-p_{A}^{1} \beta_{1}=\frac{1}{2}\left[\left(c_{A}^{2}-\lambda_{2}\right) \beta_{2}-c_{A}^{1} \beta_{1}\right]>0
$$

which implies

$$
\lambda_{2}<c_{A}^{2}-\frac{\beta_{1}}{\beta_{2}} c_{A}^{1} .
$$

If $\lambda_{1}>0$, that is, if the first inequality constraint is binding, then $\beta_{2} p_{A}^{2}-\beta_{1} p_{A}^{1}=0$ and substituting into the first two F.O.C.s yields that $\left(c_{A}^{1}-\lambda_{1}\right) \beta_{1}=\left(c_{A}^{2}+\lambda_{1}-\lambda_{2}\right) \beta_{2}$. Therefore

$$
\lambda_{2}=c_{A}^{2}-\frac{\beta_{1}}{\beta_{2}} c_{A}^{1}+\left(1+\frac{\beta_{1}}{\beta_{2}}\right) \lambda_{1}
$$

Case 1: $\frac{c_{A}^{k+1}}{c_{A}^{k}} \leq \frac{\beta_{A}^{k}}{\beta_{A}^{k+1}}$ holds for all $1 \leq k \leq n-1$

Since all the multipliers $\lambda$ are non-negative, and $\lambda_{2} \geq 0$, we know from (10) that $c_{A}^{2}-\frac{\beta_{1}}{\beta_{2}} c_{A}^{1}+\left(1+\frac{\beta_{1}}{\beta_{2}}\right) \lambda_{1} \geqslant$ $0 \Longrightarrow \lambda_{1} \geq \frac{c_{A}^{1} \beta_{1}-c_{A}^{2} \beta_{2}}{\beta_{1}+\beta_{2}}>0$ must hold. We can show that $\lambda_{2}>0$ holds by contradiction.

Suppose that $\lambda_{2}=0$. Then

$$
\begin{aligned}
& p_{A}^{2}=\frac{1}{2 \beta_{2}}+\frac{c_{A}^{2}+\lambda_{1}}{2} \\
& p_{A}^{3}=\frac{1}{2 \beta_{3}}+\frac{c_{A}^{3}-\lambda_{3}}{2} .
\end{aligned}
$$

Using these two expressions, we can see that the constraint $p_{A}^{3} \beta_{3}-p_{A}^{2} \beta_{2}$ is not binding:

$$
p_{A}^{3} \beta_{3}-p_{A}^{2} \beta_{2}=\frac{1}{2}\left[\left(c_{A}^{3}-\lambda_{3}\right) \beta_{3}-\left(c_{A}^{2}+\lambda_{1}\right) \beta_{2}\right]>0
$$

Using the inequality above,

$$
\begin{aligned}
\lambda_{3} & <c_{A}^{3}-\left(c_{A}^{2}+\lambda_{1}\right) \frac{\beta_{2}}{\beta_{3}} \\
& <c_{A}^{3}-c_{A}^{2} \frac{\beta_{2}}{\beta_{3}} \\
& \leq 0
\end{aligned}
$$

where the last inequality follows from our assumption of Case 1 (i.e., the relationship $\frac{c_{A}^{k+1}}{c_{A}^{k}} \leq \frac{\beta_{A}^{k}}{\beta_{A}^{k+1}}$ ). The derivation contradicts the fact that $\lambda_{3}$ has to be non-negative. Therefore $\lambda_{2}>0$ must hold. The same 
rationale applies to $\lambda_{3}>0, \ldots, \lambda_{n-1}>0$, which follows from induction. Hence we show that $\lambda_{k}>0$, $\forall k=1,2, \ldots, n$. Let $m:=p_{A}^{1} \beta_{A}^{1}=p_{A}^{2} \beta_{A}^{2}=\ldots=p_{A}^{n} \beta_{A}^{n}$. Substituting into the first $(n-1)$ F.O.C.s with respect to prices to solve for multipliers $\lambda$ yields

$$
\lambda_{k}=\sum_{i=1}^{k}\left[c_{A}^{i}+\frac{(1-2 m)}{\beta_{A}^{i}}\right] \quad \forall 1 \leq k \leq n-1 .
$$

And solving the last F.O.C. gives

$$
\lambda_{n-1}=-c_{A}^{n}-\frac{1-2 m}{\beta_{A}^{n}} .
$$

When $k=n-1$, the former expression $\left(\sum_{i=1}^{k}\left[c_{A}^{i}+\frac{(1-2 m)}{\beta_{A}^{i}}\right]\right)$ must be equal to the latter $\left(\lambda_{n-1}=-c_{A}^{n}-\frac{1-2 m}{\beta_{A}^{n}}\right)$, we can derive $m$ :

$$
m=\frac{1}{2}+\frac{\sum_{i=1}^{n} c_{A}^{i}}{2 \sum_{i=1}^{n} \frac{1}{\beta_{i}}}
$$

Using the expression for $m$, we can solve for the optimal prices:

$$
p_{A}^{k}=\min \left\{\frac{1}{2 \beta_{A}^{k}}+\frac{\sum_{i=1}^{n} c_{A}^{i}}{2 \sum_{i=1}^{n} \frac{\beta_{A}^{k}}{\beta_{A}^{i}}}, \frac{\alpha^{*}}{\beta_{A}^{k}}\right\} .
$$

Moreover, demand can be written as:

$$
D_{k}\left(p_{A}^{k}\right)= \begin{cases}1-m=\frac{1}{2}-\frac{\sum_{i=1}^{n} c_{A}^{i}}{2 \sum_{i=1}^{n} \frac{1}{\beta_{i}}} & \text { if } m \geq \alpha^{*} \\ 1-\alpha^{*} & \mathrm{o} / \mathrm{w}\end{cases}
$$

And the total profit can be written as:

$$
\begin{aligned}
\Pi(n, A) & =\sum_{i=1}^{n}\left(p_{A}^{i}-c_{A}^{i}\right) D_{i}(p) \\
& =\sum_{i=1}^{n} \max \left\{\frac{1}{\beta_{i}}\left(\frac{1}{2}-\frac{\sum_{i=1}^{n} c_{A}^{i}}{2 \sum_{i=1}^{n} \frac{\beta_{A}^{k}}{\beta_{A}^{i}}}\right)^{2},\left(\frac{\alpha^{*}}{\beta_{A}^{i}}-c_{A}^{i}\right)\left(1-\alpha^{*}\right)\right\}
\end{aligned}
$$

Case 2: $\frac{c_{A}^{k+1}}{c_{A}^{k}}>\frac{\beta_{A}^{k}}{\beta_{A}^{k+1}}$ holds for all $1 \leq k \leq n-1$

In this case, all $n-1$ constraints $\beta_{A}^{k} p_{A}^{k} \leq \beta_{A}^{k+1} p_{A}^{k+1}$ not binding, which implies that all the Lagrangian multipliers are zero, i.e. $\lambda_{1}=\lambda_{2}=\ldots=\lambda_{n-1}=0$ and therefore prices can be solved directly:

$$
p_{A}^{k}=\min \left\{\frac{1}{2 \beta_{A}^{k}}+\frac{c_{A}^{k}}{2}, \frac{\alpha^{*}}{\beta_{A}^{k}}\right\} \quad \forall k=1,2 \ldots, n .
$$

Since $p_{A}^{k} \beta_{A}^{k}-p_{A}^{k-1} \beta_{A}^{k-1}=\frac{1}{2}\left[c_{A}^{k} \beta_{A}^{k}-c_{A}^{k-1} \beta_{A}^{k-1}\right]>0$, the constraint $\frac{p_{A}^{k-1}}{p_{A}^{k}}<\frac{\beta_{A}^{k}}{\beta_{A}^{k-1}}$ holds, confirming that the constraints are not binding and the Lagrange multipliers should be equal to zero. 
In this case, the demand is given by:

$$
D_{k}\left(p_{A}^{k}\right)= \begin{cases}\frac{1}{2}-\frac{c_{A}^{k} \beta_{A}^{k}}{2} & \text { if } c_{A}^{k} \beta_{A}^{k} \geq 1-\alpha^{*} \\ 1-\alpha^{*} & \mathrm{o} / \mathrm{w}\end{cases}
$$

And the total profit is given by

$$
\begin{aligned}
\Pi(n, A) & =\sum_{i=1}^{n}\left(p_{A}^{i}-c_{A}^{i}\right) D_{i}\left(p_{A}^{i}\right) \\
& =\sum_{i=1}^{n} \max \left\{\frac{1}{\beta_{i}}\left(\frac{1}{2}-\frac{c_{A}^{i} \beta_{A}^{i}}{2}\right)^{2},\left(\frac{\alpha^{*}}{\beta_{A}^{i}}-c_{A}^{i}\right)\left(1-\alpha^{*}\right)\right\} .
\end{aligned}
$$

\section{Proof of Proposition 3:}

(1) Recall that $m=\frac{1}{2}+\frac{\sum_{i=1}^{n} c_{A}^{i}}{2 \sum_{i=1}^{n} \frac{1}{\beta_{i}}}$. When the size of the low-end segment is small such that $\alpha^{*} \leq$ $\frac{1}{2}\left(c_{A}^{i} \beta_{A}^{i}+1\right) \forall i=1, \ldots, n \Longrightarrow \alpha^{*} \in[0, m]$, the demand for the core product is less than the size of the high-end segment:

$$
D_{1}\left(p_{A}^{1}\right)<1-\alpha^{*}
$$

and the expansion of market for counterfeiters does not affect the target market of the luxury brand. This is because even the core product does not capture the whole market for high-end consumers. In this case, the profit function of the luxury brand can be expressed as:

$$
\Pi(n, A)=\sum_{i=1}^{n} \frac{1}{\beta_{A}^{i}}\left(\frac{1}{2}-\frac{c_{A}^{i} \beta_{A}^{i}}{2}\right)^{2} .
$$

Differentiating the profit with respect to $\left(\beta_{A}^{k}\right)^{-1}$, we can derive the impact of marginal status signalling value on the total profit of the luxury brand:

$$
\begin{aligned}
\frac{\partial \Pi(n, A)}{\partial\left(\frac{1}{\beta_{A}^{k}}\right)} & =\left(\frac{1}{2}-\frac{c_{A}^{k} \beta_{A}^{k}}{2}\right)^{2}+\frac{1}{\beta_{A}^{k}}\left(1-c_{A}^{k} \beta_{A}^{k}\right) \frac{c_{A}^{k}}{2}\left(\beta_{A}^{k}\right)^{2} \\
& =\left(\frac{1}{2}-\frac{c_{A}^{k} \beta_{A}^{k}}{2}\right)\left(\frac{1}{2}+\frac{c_{A}^{k} \beta_{A}^{k}}{2}\right) \\
& =\frac{1}{4}\left[1-\left(c_{A}^{k} \beta_{A}^{k}\right)^{2}\right]
\end{aligned}
$$

Notice that as long as the $k^{t h}$ product has a positive demand, or put differently, as long as the customers at the top of the high-end segment $(\alpha=1)$ are willing to purchase the $k^{t h}$ product, $1-c_{A}^{k} \beta_{A}^{k}>0$ must hold. The result also suggests that if the luxury brand chooses to extend the product line optimally, the marginal impact of increasing its lowest-ranked product's signal value on the overall profit should be positive. Therefore for a constant optimal portfolio choice $n^{*}$, 


$$
\frac{\partial \Pi(k, A)}{\partial\left(\frac{1}{\beta_{A}^{k}}\right)}>0 \quad 1 \leq k \leq n^{*}
$$

must hold. Recall that the marginal signalling value was defined in Equation 4 as

$$
\left(\beta_{A}^{k}\right)^{-1}=(1-\rho) \Delta \mu\left[\frac{\sigma^{2}(k-1)}{\sigma_{0}^{2}} \cdot \frac{\sigma^{2}(k-1)}{\sigma^{2}(k-1)+\left(\sigma^{k}\right)^{2}}\right] .
$$

The sign of its derive with respect to $(1-\rho)$ is positive for any product line length $k>1$ :

$$
\frac{\partial\left(\frac{1}{\beta_{A}^{k}}\right)}{\partial(1-\rho)}=\Delta \mu\left[\frac{\sigma^{2}(k-1)}{\sigma_{0}^{2}} \cdot \frac{\sigma^{2}(k-1)}{\sigma^{2}(k-1)+\left(\sigma^{k}\right)^{2}}\right]>0 .
$$

We can use the two expressions above to derive the comparative static which gives us the impact of market share of the counterfeit on profit:

$$
\frac{\partial \Pi\left(n^{*}, A\right)}{\partial(1-\rho)}=\sum_{k=1}^{n^{*}}\left[\frac{\partial \Pi(k, A)}{\partial\left(\frac{1}{\beta_{A}^{k}}\right)} \cdot \frac{\partial\left(\frac{1}{\beta_{A}^{k}}\right)}{\partial(1-\rho)}\right]>0 .
$$

Therefore when $\alpha^{*}$ is sufficiently small, the profit of luxury brand is higher if the share of counterfeit $(1-\rho)$ increases. Note that the rate at which marginal signalling value is increasing as $\rho$ decreases is proportional to $\Delta \mu$ (the "quality premium" between the luxury brand and the counterfeiter). The greater the difference in the average quality of the two outlets, the faster the signalling value of the authentic product is increasing when the counterfeit market expands, leading to a greater increase in the profit of the luxury brand.

(2) When $\alpha^{*}>m$, optimal price $p_{A}^{i}$ is tied to $\alpha^{*}$. If the high-end segment comprises a smaller share of the overall market, that is, if

$$
\begin{aligned}
\alpha^{*} & >\frac{1}{2}\left(c_{A}^{i} \beta_{A}^{i}+1\right) \quad \forall 1 \leq i \leq k, \\
\Longrightarrow \alpha^{*} & >m
\end{aligned}
$$

then an expansion of the counterfeiter squeezes out the high-end segment. With the $k$ constraints above, the optimal pricing for the first $k$ products are such that they appeal to the entire high-end segment, including the marginal customer $\left(\alpha=\alpha^{*}\right)$. Recall from Figure 1 that the demand for the $(k+1)^{t h}$ product is a subset of the demand for the $k^{\text {th }}$ and therefore when the low-end segment expands, the demand for higher-ranked products are affected first. But since all the high-end segment consumers do not buy all the peripheral products, the demand of these products may not be affected by the expansion of the counterfeiter.

Second, the expansion of the counterfeiter may affect the demand through an increase in the signalling value, which benefits all the products in the line. Hence we express the profit function function of the luxury 
brand by separating it into two terms, $\pi_{1}$ and $\pi_{2}$, that captures the profit from the first $k$ products and the remaining $(n-k)$ products, respectively:

$$
\begin{aligned}
& \Pi(n, A)=\pi_{1}+\pi_{2} \\
& =\underbrace{\rho \sum_{i=1}^{k}\left(\frac{1-\rho}{\beta_{A}^{i}}-c_{A}^{i}\right)}_{\pi_{1}: \text { total profit of the first } k \text { products that all high-end consumers buy }}+\underbrace{\sum_{i=k+1}^{n} \frac{1}{\beta_{A}^{i}}\left(\frac{1}{2}-\frac{c_{A}^{i} \beta_{A}^{i}}{2}\right)^{2}}_{\pi_{2} \text { : total profit of the remaining }(n-k) \text { products }}
\end{aligned}
$$

The sign and the magnitude of the change in profit with respect to counterfeit market share depend on how fast the market for high-end consumers $\rho$ shrinks (which affects $\pi_{1}$ ) vs. how fast the prior $\mu_{0}$ decreases as $\rho$ declines (which affects both $\pi_{1}$ and $\pi_{2}$ through the increase in signalling value $\left(\beta_{A}^{i}\right)$ ). The derivative of $\Pi(n, A)$ with respect to $(1-\rho)$ can be expressed as:

$$
\frac{\partial \Pi(n, A)}{\partial(1-\rho)}=\frac{\partial \pi_{1}}{\partial(1-\rho)}+\frac{\partial \pi_{2}}{\partial(1-\rho)}
$$

where the first term is

$$
\begin{aligned}
\frac{\partial \pi_{1}}{\partial(1-\rho)} & =\frac{\partial\left[\sum_{i=1}^{k}\left(\rho(1-\rho)^{2} \Delta \mu\left[\frac{\sigma^{2}(i-1)}{\sigma_{0}^{2}} \cdot \frac{\sigma^{2}(i-1)}{\sigma^{2}(i-1)+\left(\sigma^{k}\right)^{2}}\right]-\rho c_{A}^{i}\right)\right]}{\partial(1-\rho)} \\
& =\sum_{i=1}^{k}\left[(1-\rho)[2-3(1-\rho)] \Delta \mu\left[\frac{\sigma^{2}(i-1)}{\sigma_{0}^{2}} \cdot \frac{\sigma^{2}(i-1)}{\sigma^{2}(i-1)+\left(\sigma^{i}\right)^{2}}\right]+c_{A}^{i}\right]
\end{aligned}
$$

and the second term is

$$
\frac{\partial \pi_{2}}{\partial(1-\rho)}=\sum_{i=k+1}^{n}\left[\frac{1}{4}\left[1-\left(c_{A}^{i} \beta_{A}^{i}\right)^{2}\right] \cdot \Delta \mu\left[\frac{\sigma^{2}(i-1)}{\sigma_{0}^{2}} \cdot \frac{\sigma^{2}(i-1)}{\sigma^{2}(i-1)+\left(\sigma^{i}\right)^{2}}\right]\right] .
$$

Under the optimal product line length, it is straightforward to see that $\frac{\partial \pi_{2}\left(n^{*}\right)}{\partial(1-\rho)}>0$, using the reasoning given in Part (1). As long as the customers at the top-tier of high-end segment $(\alpha=1)$ are willing to purchase the $k^{\text {th }}$ product, $1-c_{A}^{k} \beta_{A}^{k}>0$ must hold. The sign of $\frac{\partial \pi_{1}}{\partial(1-\rho)}$ is ambiguous, but it can take a positive value for sufficiently low values of $1-\rho$. A sufficient condition for $\frac{\partial \pi_{1}}{\partial(1-\rho)}>0$ to hold is $0<(1-\rho)<\frac{2}{3}$. Therefore the profit of the luxury brand is increasing in the share of counterfeiters: $\frac{\partial \Pi(n, A)}{\partial(1-\rho)}>0$ given that $(1-\rho) \in\left[0, \frac{2}{3}\right]$.

\section{Proof of Proposition 4:}

1. Comparative Statics for Revenue: We consider the expression for total revenue, separately for each case.

\section{Case 1:}




$$
\begin{aligned}
\text { Revenue } & =\sum_{k=1}^{n} p_{A}^{k} D_{k}\left(p_{A}^{k}\right) \\
& =\sum_{k=1}^{n} \max \left\{\frac{\alpha^{*}\left(1-\alpha^{*}\right)}{\beta_{A}^{k}}, \frac{1}{4 \beta_{A}^{k}}\left(1-\left[\frac{\sum_{k=1}^{n} c_{A}^{k}}{\sum_{k=1}^{n} \frac{1}{\beta_{A}^{k}}}\right]^{2}\right)\right\}
\end{aligned}
$$

The second term in the max function is always increasing in $(1-\rho)$, which follows directly from the proof of Proposition 3. Moreover, since $\alpha^{*}=1-\rho$, the first term in the max function can be rewritten as

$$
\frac{\alpha^{*}\left(1-\alpha^{*}\right)}{\beta_{A}^{k}}=\left(\alpha^{*}\right)^{2}\left(1-\alpha^{*}\right) \underbrace{\Delta \mu \frac{\sigma^{2}(k-1)}{\sigma_{0}^{2}} \cdot \frac{\sigma^{2}(k-1)}{\sigma^{2}(k-1)+\left(\sigma^{k}\right)^{2}}}_{:=\xi} .
$$

Taking the derivative with respect to $\alpha^{*}$ (or equivalently $(1-\rho)$ ) we get

$$
2 \alpha^{*}\left(1-\alpha^{*}\right) \xi-\left(\alpha^{*}\right)^{2} \xi=\alpha^{*}\left(2-3 \alpha^{*}\right) \xi
$$

Expression in Equation (11) changes sign from positive (for $\alpha^{*} \in\left[0, \frac{2}{3}\right]$ ) to negative (for $\alpha^{*} \in\left[\frac{2}{3}, 1\right]$ ). (And as $\alpha^{*} \rightarrow 1$, the $\max$ function will always return the value of the first term for all $k \leq n$. ) Hence we should observe the derivative of the revenue with respect to the counterfeit market share to have an inverse-U shape, to first increase and then decrease in $\alpha^{*}$ (or, in $1-\rho$ ).

\section{Case 2:}

$$
\begin{aligned}
\text { Revenue } & =\sum_{k=1}^{n} p_{A}^{k} D_{k}\left(p_{A}^{k}\right) \\
& =\sum_{k=1}^{n} \max \left\{\frac{\alpha^{*}\left(1-\alpha^{*}\right)}{\beta_{A}^{k}}, \frac{1}{4 \beta_{A}^{k}}\left(1-\left[c_{A}^{k} \beta_{A}^{k}\right]^{2}\right)\right\}
\end{aligned}
$$

The derivation follows the same analysis as in Case 1.

2. Comparative Statics For Prices: Recall that the price function is continuous (and piecewise differentiable) over the support of $\alpha^{*}$.

\section{Case 1:}

$$
p_{A}^{k}= \begin{cases}\frac{1}{2 \beta_{A}^{k}}+\frac{\sum_{i=1}^{n} c_{A}^{i}}{2 \sum_{i=1}^{n} \frac{\beta_{A}^{k}}{\beta_{A}^{i}}} & \alpha^{*} \in\left[0, \frac{1}{2}\left(\frac{\frac{1}{n} \sum_{i=1}^{n} c_{A}^{k}}{\frac{1}{n} \sum_{i=1}^{n} \frac{1}{\beta_{k}}}+1\right)\right] \\ \frac{\alpha^{*}}{\beta_{A}^{k}} & \alpha^{*} \in\left[\frac{1}{2}\left(\frac{\frac{1}{n} \sum_{i=1}^{n} c_{A}^{k}}{\frac{1}{n} \sum_{i=1}^{n} \frac{1}{\beta_{k}}}+1\right), 1\right]\end{cases}
$$


For the first interval, since $\left(\beta_{A}^{k}\right)^{-1}=(1-\rho) \Delta \mu \frac{\sigma^{2}(k-1)}{\sigma_{0}^{2}} \cdot \frac{\sigma^{2}(k-1)}{\sigma^{2}(k-1)+\left(\sigma^{k}\right)^{2}}$, the term

$$
\sum_{i=1}^{n} \frac{\beta_{A}^{k}}{\beta_{A}^{i}}=\sum_{i=1}^{n}\left[\frac{\sigma^{4}(k-1)}{\sigma^{2}(k-1)+\left(\sigma^{k}\right)^{2}} \cdot \frac{\sigma^{2}(i-1)+\left(\sigma^{i}\right)^{2}}{\sigma^{4}(i-1)}\right]
$$

is not a function of $\rho$ and is independent of $\alpha^{*}$. Therefore, $\operatorname{sign}\left(\frac{\partial p_{A}^{k}}{\partial(1-\rho)}\right)=\operatorname{sign}\left(\frac{\partial\left(\beta_{A}^{k}\right)^{-1}}{\partial(1-\rho)}\right)$, which is positive.

For the second interval, when all other parameters are fixed, as $\alpha^{*}(=1-\rho)$ increases from zero to 1 , prices always increase due to the increase in the marginal signalling value of each product $\frac{\partial\left(\beta_{A}^{k}\right)^{-1}}{\partial(1-\rho)}>0$ as well as the increase in $\alpha^{*}$.

Case 2:

$$
p_{A}^{k}= \begin{cases}\frac{1}{2 \beta_{A}^{k}}+\frac{c_{A}^{k}}{2} & \alpha^{*} \in\left[0, \frac{1}{2}\left(c_{A}^{i} \beta_{A}^{i}+1\right)\right] \\ \frac{\alpha^{*}}{\beta_{A}^{k}} & \alpha^{*} \in\left[\frac{1}{2}\left(c_{A}^{k} \beta_{A}^{k}+1\right), 1\right]\end{cases}
$$

Proof for Case 2 follows the proof for Case 1.

3. Difference Between the Prices of the Core and the Lowest Ranked Product: We present the derivation of results in Case 2 since derivation for Case 1 is similar. At any given $n$, the price range (or the affordability of the luxury brand) is obtained as:

$$
p_{A}^{1}-p_{A}^{n}= \begin{cases}\frac{1}{2}\left[\left(\frac{1}{\beta_{A}^{1}}-\frac{1}{\beta_{A}^{n}}\right)+\left(c_{A}^{1}-c_{A}^{n}\right)\right] & \alpha^{*} \in\left[0, \frac{1}{2}\left(c_{A}^{i} \beta_{A}^{i}+1\right)\right] \\ \alpha^{*}\left(\frac{1}{\beta_{A}^{1}}-\frac{1}{\beta_{A}^{n}}\right) & \alpha^{*} \in\left[\frac{1}{2}\left(c_{A}^{i} \beta_{A}^{i}+1\right), 1\right]\end{cases}
$$

From Equation (4), the difference between the signalling value becomes

$$
\begin{aligned}
\frac{1}{\beta_{A}^{1}}-\frac{1}{\beta_{A}^{n}} & =(1-\rho) \Delta \mu\left[\frac{\sigma_{0}^{2}}{\sigma_{0}^{2}+\left(\sigma^{1}\right)^{2}}-\frac{\sigma^{2}(n-1)}{\sigma_{0}^{2}} \cdot \frac{\sigma^{2}(n-1)}{\sigma^{2}(n-1)+\left(\sigma^{n}\right)^{2}}\right] \\
& =(1-\rho) \Delta \mu[\chi(1)-\chi(n)]
\end{aligned}
$$

where $\chi(k):=\frac{\sigma^{2}(k-1)}{\sigma_{0}^{2}} \cdot \frac{\sigma^{2}(k-1)}{\sigma^{2}(k-1)+\left(\sigma^{k}\right)^{2}}$. As proved in (2), the marginal signalling value decreases in the number of goods purchased, thus $\chi(k)$ decreases in $k$. The derivative of the expression with respect to the market share of the counterfeits is:

$$
\frac{\partial\left(\frac{1}{\beta_{A}^{1}}-\frac{1}{\beta_{A}^{n}}\right)}{\partial(1-\rho)}=\Delta \mu[\chi(1)-\chi(n)]>0,
$$

and the sign of the derivative we are interested in is positive:

$$
\frac{\partial\left(p_{A}^{1}-p_{A}^{n}\right)}{\partial(1-\rho)}>0 .
$$

This proves that there is a positive relationship between the share of counterfeit and the affordability of the luxury brand. 


\section{Proof of Proposition 5:}

Conditional on offering $(n-1)$ products, the net marginal profit of offering one more product is $\Pi(n, A)-$ $\Pi(n-1, A)$. To simplify notations, let

$$
\Delta \Pi(n) \equiv \Pi(n, A)-\Pi(n-1, A)
$$

and $\alpha^{1+}$ and $\alpha^{2+}$ be the thresholds for the share of low-end segments at which the expansion of counterfeits begins to affect the pricing strategy of the luxury brand, where $\alpha^{1+}:=\frac{1}{2}\left(\frac{\frac{1}{n} \sum_{i=1}^{n} c_{A}^{k}}{\frac{1}{n} \sum_{i=1}^{n} \frac{1}{\beta_{k}}}+1\right)$ for Case 1 and $\alpha^{2+}:=\frac{1}{2}\left(c_{A}^{n} \beta_{A}^{n}+1\right)$ for Case 2.

Case 1: When $c_{A}^{n} \beta_{A}^{n} \leq c_{A}^{n-1} \beta_{A}^{n-1}$ holds, the difference in profit due to adding the $n^{\text {th }}$ product becomes:

$$
\Pi(n, A)-\Pi(n-1, A)= \begin{cases}\frac{1}{\beta_{A}^{n}}\left(1-\alpha^{1+}\right)^{2} & \alpha^{*} \in\left[0, \alpha^{1+}\right] \\ \frac{1-\alpha^{*}}{\beta_{A}^{n}}\left(\alpha^{*}-c_{A}^{n} \beta_{A}^{n}\right) & \alpha^{*} \in\left[\alpha^{1+}, 1\right]\end{cases}
$$

Notice that $\alpha^{1+}$ decreases in $n$.

$\Delta \Pi(n)$ is continuous at $\alpha^{1+}$ and is always positive when $\alpha^{*}$ is below this cutoff: it is optimal to extend the product line up to the affordability of top-tier high-end consumers (13) as the share of the counterfeiter $\alpha^{*}=(1-\rho)$ increases (but is still not high enough to tamper with the sales of the luxury brand).

However, offering multiple products also increases the prices of the brand, so the interval $\left[0, \alpha^{1+}\right]$ will eventually shrink as $n$ increases. In that case, as $\alpha^{*}$ increases, the optimal $n^{*}$ is likely to be bound by the constraint (12) in addition to (13):

$$
\min _{i \leq n^{*}}\left\{\alpha^{*}-c_{A}^{i} \beta_{A}^{i}\right\} \geq 0 \Longleftrightarrow \max _{i \leq n^{*}} c_{A}^{i} \beta_{A}^{i} \leq \alpha^{*}
$$

For any given $n,(12)$ is less likely to bind when $\alpha^{*}$ increases. This suggests that even when the fraction of high-end consumers are squeezed due to an expansion of the counterfeiter market, the luxury brand should extend its product line in response to an increase in the willingness to pay of their loyal customers.

Case 2: When $c_{A}^{n} \beta_{A}^{n}>c_{A}^{n-1} \beta_{A}^{n-1}$ holds,

$$
\Pi(n, A)-\Pi(n-1, A)= \begin{cases}\frac{1}{\beta_{A}^{n}}\left(1-\alpha^{2+}\right)^{2} & \alpha^{*} \in\left[0, \alpha^{2+}\right] \\ \frac{1-\alpha^{*}}{\beta_{A}^{n}}\left(\alpha^{*}-c_{A}^{n} \beta_{A}^{n}\right) & \alpha^{*} \in\left[\alpha^{2+}, 1\right]\end{cases}
$$

Again, $\alpha^{2+}$ increases in $n$. For demand to be nonzero, the $n^{\text {th }}$ product should appeal at least to the top-tier high-end consumers with $\alpha=1$. This imposes a condition on the optimal product line length $n^{*}$ :

$$
c_{A}^{n *} \beta_{A}^{n *} \leq 1
$$

$\Delta \Pi(n)$ is continuous at $\alpha^{2+}$ and is always positive when $\alpha^{*}$ is below this cutoff. When the counterfeiter market is small enough (so that it does not tamper with the sales of the luxury brand), the product line decision does not depend on the share of the counterfeiter. Due to lack of economies of scope, even the 
lowest-ranked product will be offered at a price only a small portion of the high-end segment will buy. Therefore, compared to Case 1, in Case 2, the range of market share within which the counterfeiter does not affect product line decision is wider.

If the share of counterfeiter begins to squeeze the high-end segment, then the luxury brand should extend its product line in response to the increasing willingness to pay of their loyal customers.

Combining the two cases, the optimal product line length $n^{*}$ is a monotonically increasing step function of $\alpha^{*}$.

\section{Proof of Proposition 6:}

The derivative of the marginal signalling value $\left(\beta_{A}^{k}\right)^{-1}=(1-\rho) \Delta \mu \frac{\sigma^{2}(k-1)}{\sigma_{0}^{2}} \cdot \frac{\sigma^{2}(k-1)}{\sigma^{2}(k-1)+\left(\sigma^{k}\right)^{2}}$ with respect to the quality premium has a positive sign:

$$
\frac{\partial\left(\beta_{A}^{k}\right)^{-1}}{\partial \Delta \mu}>0 \forall k=1, \ldots, n
$$

The rest directly follows the proofs of Propositions 3 and 4 .

\section{Proof of Proposition 7:}

We first prove the expression of the price and profit function. Let's fix $n$, the length of product line. Also assume that the price of all products weakly exceed their production cost i.e., $p_{A} \geq c_{A}$. Since the profit function is piecewise differentiable with respect to prices, we consider a set of price intervals $P=$ $\left(\frac{\alpha^{*}}{\beta_{A}^{n}}, \frac{\alpha^{*}}{\beta_{A}^{n-1}}\right] \cup\left(\frac{\alpha^{*}}{\beta_{A}^{n-1}}, \frac{\alpha^{*}}{\beta_{A}^{n-2}}\right] \cup \ldots \cup\left(\frac{\alpha^{*}}{\beta_{A}^{2}}, \frac{\alpha^{*}}{\beta_{A}^{1}}\right]$ within each the profit function is continuous and differentiable.

Suppose $p_{A} \in\left(\frac{\alpha^{*}}{\beta_{A}^{m+1}}, \frac{\alpha^{*}}{\beta_{A}^{m}}\right]$ holds for any $1 \leq m \leq n-1$. Note that when the prices are set in this range, the entire high-end segment buys the $m^{t h}$ product. Let's see how the profit function behaves when the price is declining.

$$
\begin{aligned}
\frac{\partial \Pi(A, n)}{\partial\left(-p_{A}\right)} & =\underbrace{-m\left(1-\alpha^{*}\right)-\sum_{k=m+1}^{n}\left(1-\beta_{A}^{k} p_{A}\right)}_{\text {profit loss due to lower price }}+\underbrace{\left(p_{A}-c_{A}\right) \sum_{k=m+1}^{n} \beta_{A}^{k}}_{\text {profit gain due to higher demand for the last }(n-m) \text { products }} \\
& =-n+m \alpha^{*}+\left(2 p_{A}-c_{A}\right) \sum_{k=m+1}^{n} \beta_{A}^{k}
\end{aligned}
$$

which is positive if and only if

$$
p_{A}>\frac{1}{2}\left[\frac{n-m \alpha^{*}}{\sum_{k=m+1}^{n} \beta_{A}^{k}}+c_{A}\right] .
$$

If the derivative is negative, then $\frac{1}{2}\left[\frac{n-m \alpha^{*}}{\sum_{k=m+1}^{n} \beta_{A}^{k}}+c_{A}\right] \geq \frac{\alpha^{*}}{\beta_{A}^{m}} \Longleftrightarrow \alpha^{*} \leq \frac{\frac{n}{\sum_{k=m+1_{A}^{k}}^{n}+c_{A}}}{\sum_{k=m+1}^{n} \beta_{A}^{k}+\frac{\alpha_{A}^{2}}{\beta^{m}}}:=\bar{\alpha}^{m}$, then $p_{A}^{*} \geq$ $\frac{\alpha^{*}}{\beta_{A}^{m}}$. If on the other hand the derivative is positive, that is, if $\frac{1}{2}\left[\frac{n-m \alpha^{*}}{\sum_{k=m+1}^{n} \beta_{A}^{k}}+c_{A}\right] \leq \frac{\alpha^{*}}{\beta_{A}^{m+1}} \Longleftrightarrow \alpha^{*} \geq$ 
$\frac{\frac{n}{\sum_{k=m+1}^{n} \beta_{A}^{k}}+c_{A}}{\frac{m}{\sum_{k=m+1}^{n} \beta_{A}^{k}}+\frac{2}{\beta_{A}^{m+1}}}:=\underline{\alpha}^{m+1}$, then $p_{A}^{*} \leq \frac{\alpha^{*}}{\beta_{A}^{m+1}}$. Finally, if $\alpha^{*} \in\left(\bar{\alpha}^{m}, \underline{\alpha}^{m+1}\right]^{25}$, then $p_{A}^{*} \in\left(\frac{\alpha^{*}}{\beta_{A}^{m+1}}, \frac{\alpha^{*}}{\beta_{A}^{m}}\right]$.

Next we show that the relationships demonstrated applies to all the intervals in $1 \leq m \leq n-1$ and the intervals are connected and are well-defined, by ensuring that $\bar{\alpha}^{m}>\bar{\alpha}^{m-1}$ and $\underline{\alpha}^{m}-\bar{\alpha}^{m}<0$. First,

$$
\begin{aligned}
\bar{\alpha}^{m}-\bar{\alpha}^{m-1} & =\frac{\left[\frac{n \beta_{A}^{m}}{\sum_{k=m+1}^{n} \beta_{A}^{k}}+c_{A} \beta_{A}^{m}\right]\left(\frac{(m-1) \beta_{A}^{m-1}}{\sum_{k=m}^{n} \beta_{A}^{k}}+2\right)-\left[\frac{n \beta_{A}^{m-1}}{\sum_{k=m}^{n} \beta_{A}^{k}}+c_{A} \beta_{A}^{m-1}\right]\left(\frac{m \beta_{A}^{m}}{\sum_{k=m+1}^{n} \beta_{A}^{k}}+2\right)}{\left(\frac{m \beta_{A}^{m}}{\sum_{k=m+1}^{n} \beta_{A}^{k}}+2\right)\left(\frac{(m-1) \beta_{A}^{m-1}}{\sum_{k=m}^{n} \beta_{A}^{k}}+2\right)} \\
& =\frac{\frac{n(m-1) \beta_{A}^{m} \beta_{A}^{m-1}-n m \beta_{A}^{m} \beta_{A}^{m-1}}{\sum_{k=m+1}^{n} \beta_{A}^{k} \sum_{k=m}^{n} \beta_{A}^{k}}+2\left[\frac{n \beta_{A}^{m}}{\sum_{k=m+1}^{n} \beta_{A}^{k}}-\frac{n \beta_{A}^{m-1}}{\sum_{k=m}^{n} \beta_{A}^{k}}\right]+\left(\frac{(m-1) \beta_{A}^{m-1}}{\sum_{k=m}^{n} \beta_{A}^{k}}-\frac{m \beta_{A}^{m}}{\sum_{k=m+1}^{n} \beta_{A}^{k}}\right) \cdot c_{A} \beta_{A}^{1}}{\left(\frac{m \beta_{A}^{m}}{\sum_{k=m+1}^{n} \beta_{A}^{k}}+2\right)\left(\frac{(m-1) \beta_{A}^{m-1}}{\sum_{k=m}^{n} \beta_{A}^{k}}+2\right)} \\
& =\frac{-n \beta_{A}^{m} \beta_{A}^{m-1}+(2 n-m)\left(\beta_{A}^{m}\right)^{2}+\sum_{k=m+1}^{n}\left[\left((m-1) \beta_{A}^{m-1}-m \beta_{A}^{m}\right) \cdot c_{A} \beta_{A}^{1}-2 n\left(\beta_{A}^{m-1}-\beta_{A}^{m}\right)\right] \beta_{A}^{k}}{\left(\frac{m \beta_{A}^{1}}{\sum_{k=m+1}^{n} \beta_{A}^{k}}+2\right)\left(\frac{(m-1) \beta_{A}^{1}}{\sum_{k=m}^{n} \beta_{A}^{k}}+2\right)\left(\sum_{k=m+1}^{n} \beta_{A}^{k} \cdot \sum_{k=m}^{n} \beta_{A}^{k}\right)} \\
& >\frac{-n \beta_{A}^{m} \beta_{A}^{m-1}+(2 n-m)\left(\beta_{A}^{m}\right)^{2}+\sum_{k=m+1}^{n}\left[(2 n-m)\left(\beta_{A}^{m}-\beta_{A}^{m-1}\right)+\beta_{A}^{m-1}\right] \beta_{A}^{k}}{\left(\frac{m \beta_{A}^{1}}{\sum_{k=m+1}^{n} \beta_{A}^{k}}+2\right)\left(\frac{(m-1) \beta_{A}^{1}}{\sum_{k=m}^{n} \beta_{A}^{k}}+2\right)\left(\sum_{k=m+1}^{n} \beta_{A}^{k} \cdot \sum_{k=m}^{n} \beta_{A}^{k} \beta_{A}^{k}<1\right)} \\
& >\frac{2 \beta_{A}^{m}\left[(2 n-m) \beta_{A}^{m}-n \beta_{A}^{m-1}\right]}{\left(\frac{m \beta_{A}^{1}}{\sum_{k=m+1}^{n} \beta_{A}^{k}}+2\right)\left(\frac{(m-1) \beta_{A}^{1}}{\sum_{k=m}^{n} \beta_{A}^{k}}+2\right)\left(\sum_{k=m+1}^{n} \beta_{A}^{k} \cdot \sum_{k=m}^{n} \beta_{A}^{k}\right)} \\
& >0
\end{aligned}
$$

where the last inequality follows that $(2 n-m) \beta_{A}^{m}-n \beta_{A}^{m-1}>n\left(\beta_{A}^{m}-\beta_{A}^{m-1}\right)>0$. This implies that $\bar{\alpha}^{m}$ increases in $m$. Also,

$$
\begin{aligned}
\underline{\alpha}^{m}-\bar{\alpha}^{m} & =\frac{\frac{n}{\sum_{k=m}^{n} \beta_{A}^{k}}+c_{A}}{\frac{m-1}{\sum_{k=m}^{n} \beta_{A}^{k}}+\frac{2}{\beta_{A}^{m}}-\frac{n}{\sum_{k=m+1}^{n} \beta_{A}^{k}}+c_{A}} \frac{m}{\sum_{k=m+1}^{n} \beta_{A}^{k}}+\frac{2}{\beta_{A}^{m}} \\
& =\frac{\frac{n}{\sum_{k=m}^{n} \beta_{A}^{k} \sum_{k=m+1}^{n} \beta_{A}^{k}}+\frac{2}{\beta_{A}^{m}}\left(\frac{n}{\sum_{k=m}^{n} \beta_{A}^{k}}-\frac{n}{\sum_{k=m+1}^{n} \beta_{A}^{k}}\right)+\left(\frac{m}{\sum_{k=m+1}^{n} \beta_{A}^{k}}-\frac{m-1}{\sum_{k=m}^{n} \beta_{A}^{k}}\right) c_{A}}{\left(\frac{m-1}{\sum_{k=m}^{n} \beta_{A}^{k}}+\frac{2}{\beta_{A}^{m}}\right)\left(\frac{m}{\sum_{k=m+1}^{n} \beta_{A}^{k}}+\frac{2}{\beta_{A}^{m}}\right)} \\
& <\frac{n-2 n+\left(m \beta_{A}^{m}+\sum_{k=m+1}^{n} \beta_{A}^{k}\right) \cdot \frac{1}{\beta_{A}^{n}}}{\left(\frac{m-1}{\sum_{k=m}^{n} \beta_{A}^{k}}+\frac{2}{\beta_{A}^{m}}\right)\left(\frac{m}{\sum_{k=m+1}^{n} \beta_{A}^{k}}+\frac{2}{\beta_{A}^{m}}\right)\left(\sum_{k=m}^{n} \beta_{A}^{k} \cdot \sum_{k=m+1}^{n} \beta_{A}^{k}\right)}\left(\text { since } c_{A} \beta_{A}^{n}<1\right) \\
& <0
\end{aligned}
$$

which implies that $\underline{\alpha}^{m}<\bar{\alpha}^{m}, \forall 1 \leq m \leq n-1$.

Combining the results from above, keeping the product line length $n$ constant, the optimal pricing function is a monotonically decreasing function in $\alpha^{*}$, specifically:

\footnotetext{
${ }^{25}$ Since $1 / \beta_{A}^{m+1}<1 / \beta_{A}^{m}$, we know that $\bar{\alpha}^{m}<\underline{\alpha}^{m+1}$.
} 


$$
p_{A}^{*}= \begin{cases}\frac{1}{2}\left(\frac{n}{\sum_{k=1}^{n} \beta_{A}^{k}}+c_{A}\right) & \alpha^{*} \in\left(0, \underline{\alpha}^{1}\right] \\ \frac{\alpha^{*}}{\beta_{A}^{m}} & \alpha^{*} \in\left(\underline{\alpha}^{m}, \bar{\alpha}^{m}\right] \quad, \forall 1 \leq \mathrm{m} \leq \mathrm{n}-1 \\ \frac{\alpha^{*}}{\beta_{A}^{m+1}} & \alpha^{*} \in\left(\bar{\alpha}^{m}, \underline{\alpha}^{m+1}\right]\end{cases}
$$

Note that $\bar{\alpha}^{0}=\underline{\alpha}^{1}$ and thus the last two intervals in the price function can be merged into one $\left(\bar{\alpha}^{m-1}, \bar{\alpha}^{m}\right]$.

If the luxury brand is not making negative profits with the $n^{\text {th }}$ product, it has to charge a higher price than its cost, which implies that $c_{A} \beta_{A}^{i}<1$ holds for all $1 \leq i \leq n$. However, depending on the value of $\alpha^{*} \in(0,1)$, the derivative of the profit function $\Pi^{*}(n, A)$ with respect to $n$ at $n=1$ takes on different expressions due to the piecewise structure of optimal pricing. Therefore we study the optimal product line length decision when the share of low-end segment $\alpha^{*}$ belongs to different intervals : $\left(0, \bar{\alpha}^{0}(n)\right] \cup\left(\bar{\alpha}^{0}(n), \bar{\alpha}^{1}(n)\right] \cup \ldots \cup\left(\bar{\alpha}^{n-1}(n), 1\right]$. Let $\beta(n) \equiv \sum_{i=1}^{n} \beta_{A}^{i}$ and $\beta^{\prime}(n) \equiv \beta(n)-\beta(n-1)$ with slight abuse of notation.

(a) Interval 1: $\alpha^{*} \in\left(0, \min _{n \leq n^{*}}\left\{\bar{\alpha}^{0}(n)\right\}\right]$

$$
\Pi\left(p_{A}^{*}, n\right)=\frac{1}{\beta(n)}\left(\frac{n}{2}-\frac{c_{A} \beta(n)}{2}\right)^{2}
$$

Note that $\frac{1}{\beta(n) / n}>c_{A}$ always holds as long as $c_{A} \beta_{A}^{i}<1$ holds for all $1 \leq i \leq n$.

$$
\begin{aligned}
\frac{\partial \Pi\left(p_{A}^{*}, n\right)}{\partial n} & =\frac{\beta(n)\left(n-c_{A} \beta(n)\right)\left(\frac{1}{2}-\frac{c_{A}}{2} \beta^{\prime}(n)\right)-\beta^{\prime}(n)\left(\frac{n}{2}-\frac{c_{A}}{2} \beta(n)\right)^{2}}{\beta^{2}(n)}= \\
& =\left(\frac{n}{\beta(n)}-c_{A}\right)\left(\frac{1}{2}-\frac{c_{A}}{2} \beta^{\prime}(n)\right)-\beta^{\prime}(n)\left(\frac{n}{2 \beta(n)}-\frac{c_{A}}{2}\right)^{2} \\
& =\left(\frac{n}{2 \beta(n)}-\frac{c_{A}}{2}\right)\left(1-\frac{c_{A}}{2} \beta^{\prime}(n)-\frac{n \beta^{\prime}(n)}{2 \beta(n)}\right) \\
& \frac{1}{2}\left(\frac{n}{\beta(n)}-c_{A}\right)\left(1+\frac{\beta_{A}^{n}}{2}\left[\frac{n}{\beta(n)}-c_{A}\right]\right)
\end{aligned}
$$

Hence the optimal $n^{*}$ should satisfy $\frac{\partial \Pi^{*}\left(n^{*}, A\right)}{\partial n} \geq 0$ and $\frac{\partial \Pi^{*}\left(n^{*}+1, A\right)}{\partial n} \leq 0$ which suggest the following two inequalities should hold:

$$
\frac{n^{*}}{\beta\left(n^{*}\right)}-c_{A} \geq 0
$$

and

$$
\frac{n^{*}+1}{\beta\left(n^{*}+1\right)}-c_{A}<0
$$

(b) Interval 2: $\alpha^{*} \in\left(\bar{\alpha}^{m-1}(n), \bar{\alpha}^{m}(n)\right], \quad \forall 1 \leq m \leq n$. In this case, the profit function is:

$$
\Pi\left(p_{A}^{*}, n\right)=\left(\frac{\alpha^{*}}{\beta_{A}^{m}}-c_{A}\right)\left[n-\alpha^{*}\left(m+\frac{\beta(n)-\beta(m)}{\beta_{A}^{m}}\right)\right]
$$


Given $m$, we take the derivative of $\Pi$ with respect to $n$ :

$$
\begin{aligned}
\frac{\partial \Pi\left(p_{A}^{*}, n\right)}{\partial n} & =\left(\frac{\alpha^{*}}{\beta_{A}^{m}}-c_{A}\right)\left(1-\alpha^{*} \frac{\beta^{\prime}(n)}{\beta_{A}^{m}}\right) \\
& =\alpha^{*}\left(\frac{\alpha^{*}}{\beta_{A}^{m}}-c_{A}\right)\left(\frac{1}{\alpha^{*}}-\frac{\beta_{A}^{n}}{\beta_{A}^{m}}\right)
\end{aligned}
$$

This shows that $\operatorname{sign}\left(\frac{\partial \Pi^{*}(s, n)}{\partial n}\right)=\operatorname{sign}\left(\frac{1}{\alpha^{*}}-\frac{\beta_{A}^{n}}{\beta_{A}^{m}}\right)$ holds. When $\alpha^{*}$ is constant, since $m$ is a function of $n$, the optimal $n^{*}$ should satisfy

$$
\frac{1}{\alpha^{*}}-\frac{\beta_{A}^{n *}}{\beta_{A}^{m(n *)}} \geq 0
$$

and

$$
\frac{1}{\alpha^{*}}-\frac{\beta_{A}^{n *}}{\beta_{A}^{m(n *)}}<0
$$

It is easy to see that when $\alpha^{*} \rightarrow 1, \frac{1}{\alpha^{*}}-\frac{\beta_{A}^{n}}{\beta_{A}^{m(n)}}<0$ always holds for any $n-m(n)>1$ because $\beta_{A}^{n}>\beta_{A}^{m(n)}$. This implies that as the market share of counterfeiter approaches 1, it is never optimal to offer multiple products.

\section{Derivation of the Results in Section 4.2:}

When segmentation is endogenous, for all the peripheral products $k \geq 2$, the greater the quality premium $\Delta \mu$, the more valuable their signalling value becomes (due to the lower prior on the quality of products). The luxury brand can charge higher prices and since their demand function is $D_{k}\left(p_{A}^{k}\right)=1-p_{A}^{k} \beta_{A}^{k}$, it can obtain higher profits. This is consistent with the results from our benchmark model.

But the demand for the core product, differently from the demand of the peripheral products, depends on the status signalling sensitivity of the consumer who is indifferent between purchasing from the counterfeit and the luxury brand, since

$$
D_{1}\left(p_{A}^{1}\right)=1-\alpha^{*}
$$

which is tied to $\rho^{*}$.

We can prove that there is a unique equilibrium solution for $\rho^{*}$ for any given set of parameter values under endogenous segmentation, but the change in price of the core product may be positively or negatively correlated with the overall profit.

First note that, individual rationality (IR) constraint requires the marginal consumer who is indifferent between buying from the counterfeit and the luxury brand has a higher sensitivity compared to the consumer who is indifferent between buying a counterfeit and nothing:

$$
\alpha^{*} \geq \underline{\alpha}
$$


which implies

$$
\begin{array}{lll}
\frac{p_{A}^{1}-p_{C}}{\mu_{A}-\mu_{C}} \cdot \frac{\sigma_{0}^{2}+\left(\sigma^{1}\right)^{2}}{\sigma_{0}^{2}} & \geq \frac{p_{C}\left[\sigma_{0}^{2}+\left(\sigma^{1}\right)^{2}\right]}{\left(\sigma^{1}\right)^{2} \mu_{0}+\sigma_{0}^{2} \mu_{C}} \\
\Rightarrow & \frac{p_{A}^{1}-p_{C}}{\mu_{A}-\mu_{C}} & \geq \frac{\sigma_{0}^{2} p_{C}}{\left(\sigma^{1}\right)^{2} \mu_{0}+\sigma_{0}^{2} \mu_{C}} \\
\Rightarrow & \frac{p_{A}^{1}-p_{C}}{p_{C}} & \geq \frac{\sigma_{0}^{2} \Delta \mu}{\left(\sigma^{1}\right)^{2} \rho \Delta \mu+\left[\sigma_{0}^{2}+\left(\sigma^{1}\right)^{2}\right] \mu_{C}} .
\end{array}
$$

Second notice that the marginal consumer has a sensitivity that is weakly lower than the sensitivity of the most sensitive consumer, $\alpha^{*} \leq 1$, implying

$$
\begin{array}{ll}
\frac{p_{A}^{1}-p_{C}}{\mu_{A}-\mu_{C}} \cdot \frac{\sigma_{0}^{2}+\left(\sigma^{1}\right)^{2}}{\sigma_{0}^{2}} & \leq 1 \\
\Rightarrow \quad p_{A}^{1}-p_{C} & \leq \frac{\sigma_{0}^{2} \Delta \mu}{\sigma_{0}^{2}+\left(\sigma^{1}\right)^{2}}
\end{array}
$$

where (14),(15) define the lower and upper bound of $p_{A}^{1}$ respectively. Equations (6), (7), (14), and (15) ensure that the segment intervals $\left(\left[\underline{\alpha}, \alpha^{*}\right] \cup\left[\alpha^{*}, 1\right]\right)$ are well defined.

Using the endogenous expression (6) in the definition of market share $\rho$, we obtain:

$$
\rho=1-\alpha^{*}=1-\frac{p_{A}^{1}-p_{C}}{\mu_{A}-\mu_{C}} \cdot \frac{\sigma_{0}^{2}+\left(\sigma^{1}\right)^{2}}{\sigma_{0}^{2}}
$$

The profit function of the counterfeiter is given by

$$
\begin{aligned}
\Pi(1, C) & =\left(p_{C}-c_{C}\right) \cdot\left(\alpha^{*}-\underline{\alpha}\right) \\
& =\left(p_{C}-c_{C}\right) \cdot\left[\frac{p_{A}^{1}-p_{C}}{\mu_{A}-\mu_{C}} \cdot \frac{\sigma_{0}^{2}+\left(\sigma^{1}\right)^{2}}{\sigma_{0}^{2}}-\frac{p_{C}}{\left(\sigma^{1}\right)^{2} \mu_{0}+\sigma_{0}^{2} \mu_{C}} \cdot\left(\sigma_{0}^{2}+\left(\sigma^{1}\right)^{2}\right)\right]
\end{aligned}
$$

F.O.C. with respect to price yields

$$
\begin{aligned}
p_{C}^{*} & =\frac{1}{2}\left[c_{C}+p_{A}^{1} \cdot \frac{\left(\sigma^{1}\right)^{2} \mu_{0}+\sigma_{0}^{2} \mu_{C}}{\left(\sigma^{1}\right)^{2} \mu_{0}+\sigma_{0}^{2} \mu_{A}}\right] \\
\text { s.t. } \quad \mu_{0} & =\rho \mu_{A}+(1-\rho) \mu_{C}
\end{aligned}
$$

Substituting for $p_{C}$ in Equation (16), we obtain a direct relationship between $\rho$ and $p_{A}^{1}$ : 


$$
\begin{gathered}
\rho=1-\frac{p_{A}^{1}\left[1-\frac{1}{2} \frac{\left(\sigma^{1}\right)^{2} \mu_{0}+\sigma_{0}^{2} \mu_{C}}{\left(\sigma^{1}\right)^{2} \mu_{0}+\sigma_{0}^{2} \mu_{A}}\right]-\frac{1}{2} c_{C}}{\mu_{A}-\mu_{C}} \\
(1-\rho) \Delta \mu=p_{A}^{1}\left[1-\frac{1}{2} \frac{\rho \Delta \mu+\left[1+\frac{\sigma_{0}^{2}}{\sigma_{1}^{2}}\right] \mu_{C}}{\rho \Delta \mu+\left[1+\frac{\sigma_{0}^{2}}{\sigma_{1}^{2}} \cdot \frac{\mu_{A}}{\mu_{C}}\right] \mu_{C}}\right]-\frac{1}{2} c_{C} \\
2(1-\rho) \Delta \mu+c_{C}=p_{A}^{1}\left[\frac{\rho \Delta \mu+\left[1+\frac{\sigma_{0}^{2}}{\sigma_{1}^{2}} \cdot\left(\frac{2 \mu_{A}}{\mu_{C}}-1\right)\right] \mu_{C}}{\rho \Delta \mu+\left[1+\frac{\sigma_{0}^{2}}{\sigma_{1}^{2}} \cdot \frac{\mu_{A}}{\mu_{C}}\right] \mu_{C}}\right]
\end{gathered}
$$

which gives the price as a function of $\rho$ :

$$
p_{A}^{1}=\frac{\rho \Delta \mu+\left[1+\frac{\sigma_{0}^{2}}{\sigma_{1}^{2}} \cdot \frac{\mu_{A}}{\mu_{C}}\right] \mu_{C}}{\rho \Delta \mu+\left[1+\frac{\sigma_{0}^{2}}{\sigma_{1}^{2}} \cdot\left(\frac{2 \mu_{A}}{\mu_{C}}-1\right)\right] \mu_{C}} \cdot\left(2(1-\rho) \Delta \mu+c_{C}\right) .
$$

Let's investigate how the market share $\rho$ responds to a change in the price of the core product $p_{A}^{1}$. To this end, we apply the implicit function theorem by differentiating both sides of the above equation with respect to $p_{A}^{1}$ :

$$
\begin{gathered}
1=\partial\left(\frac{\rho \Delta \mu+\left[1+\frac{\sigma_{0}^{2}}{\sigma_{1}^{2}} \cdot \frac{\mu_{A}}{\mu_{C}}\right] \mu_{C}}{\rho \Delta \mu+\left[1+\frac{\sigma_{0}^{2}}{\sigma_{1}^{2}} \cdot\left(\frac{2 \mu_{A}}{\mu_{C}}-1\right)\right] \mu_{C}} \cdot\left(2(1-\rho) \Delta \mu+c_{C}\right)\right) / \partial p_{A}^{1} \\
\rho \Delta \mu+\left[1+\frac{\sigma_{0}^{2}}{\sigma_{1}^{2}} \cdot\left(\frac{2 \mu_{A}}{\mu_{C}}-1\right)\right] \mu_{C}=\Delta \mu\left[2(1-2 \rho) \Delta \mu-2\left[1+\frac{\sigma_{0}^{2}}{\sigma_{1}^{2}} \cdot \frac{\mu_{A}}{\mu_{C}}\right] \mu_{C}+c_{C}-p_{A}^{1}\right] \frac{\partial \rho}{\partial p_{A}} \\
\frac{\partial \rho}{\partial p_{A}}=\frac{\rho+\left[1+\frac{\sigma_{0}^{2}}{\sigma_{1}^{2}} \cdot\left(\frac{2 \mu_{A}}{\mu_{C}}-1\right)\right] \frac{\mu_{C}}{\Delta \mu}}{\left[2\left(-2 \rho \Delta \mu+\left(1-\frac{\sigma_{0}^{2}}{\sigma_{1}^{2}}\right) \mu_{A}\right)+c_{C}-p_{A}^{1}\right]}
\end{gathered}
$$

Note that the numerator of RHS is always positive and the denominator of RHS is negative on $\rho \in(0,1)$ if $\frac{\sigma_{0}^{2}}{\sigma_{1}^{2}} \geq 1$, which leads to a negative relationship between $\rho$ and $p_{A}$, i.e. $\frac{\partial \rho}{\partial p_{A}}<0$. Hence if $\sigma_{0}^{2} \geq \sigma_{1}^{2}$ holds $^{26}$, then an increase in the price of the core product leads to a smaller high-end segment and in turn lowers the prior mean, thereby building up more valuable signals for all the products offered by the luxury brands. Therefore the problem of the luxury brand to choose the optimal prices is equivalent to choosing an optimal market share $\rho$.

Recall that the marginal consumer buys one and only one product (i.e. the core product) and the demand of peripheral products is a strict subset of the demand of the core products. We can rewrite the profit as a function of $\rho$ :

\footnotetext{
${ }^{26}$ This condition simply assumes that the signals carried by the core products should be weakly more precise than the prior.
} 


$$
\Pi(n, A)=\underbrace{\max \left\{\rho\left(p_{A}^{1}-c_{A}^{1}\right), 0\right\}}_{\pi_{1} \text { :total profit of the core product }}+\underbrace{\sum_{i=2}^{n} \frac{1}{\beta_{A}^{i}}\left(\frac{1}{2}-\frac{c_{A}^{i} \beta_{A}^{i}}{2}\right)^{2}}_{\pi_{2} \text { : total profit of the remaining }(n-1) \text { products }}
$$

Substituting for $p_{A}^{1}$ and $\left\{\beta_{A}^{i}\right\}_{i=2, \ldots, n}$ and differentiating each term w.r.t. $\rho$,

$$
\begin{aligned}
& \frac{\partial \pi_{1}}{\partial \rho}{ }_{\mid \pi_{1}>0}=[\underbrace{\frac{\rho \Delta \mu+\left[1+\frac{\sigma_{0}^{2}}{\sigma_{1}^{2}} \cdot \frac{\mu_{A}}{\mu_{C}}\right] \mu_{C}}{\rho \Delta \mu+\left[1+\frac{\sigma_{0}^{2}}{\sigma_{1}^{2}} \cdot\left(\frac{2 \mu_{A}}{\mu_{C}}-1\right)\right] \mu_{C}} \cdot\left(2(1-\rho) \Delta \mu+c_{C}\right)-c_{A}}_{>0}]+\rho \cdot \underbrace{\frac{\left[2\left(-2 \rho \Delta \mu+\left(1-\frac{\sigma_{0}^{2}}{\sigma_{1}^{2}}\right) \mu_{A}\right)+c_{C}-p_{A}^{1}\right]}{\rho+\left[1+\frac{\sigma_{0}^{2}}{\sigma_{1}^{2}} \cdot\left(\frac{2 \mu_{A}}{\mu_{C}}-1\right)\right] \frac{\mu_{C}}{\Delta \mu}}}_{<0} \\
& \frac{\partial \pi_{2}}{\partial \rho}=-\sum_{i=2}^{n}\left[\frac{1}{4}\left[1-\left(\frac{c_{A}^{i}}{(1-\rho) \Delta \mu\left[\frac{\sigma^{2}(i-1)}{\sigma_{0}^{2}} \cdot \frac{\sigma^{2}(i-1)}{\sigma^{2}(i-1)+\left(\sigma^{2}\right)^{2}}\right]}\right)^{2}\right] \cdot \Delta \mu\left[\frac{\sigma^{2}(i-1)}{\sigma_{0}^{2}} \cdot \frac{\sigma^{2}(i-1)}{\sigma^{2}(i-1)+\left(\sigma^{i}\right)^{2}}\right]\right] \leq 0
\end{aligned}
$$

we observe that $\operatorname{sign}\left(\frac{\partial \pi_{1}}{\partial \rho}\right)$ is ambiguous for $\rho \in(0,1)$. However, we know that:

$$
\begin{gathered}
\frac{\partial \Pi(n, A)}{\partial \rho}(\rho=0)=\underbrace{\frac{\partial \pi_{1}}{\partial \rho}(\rho=0)}_{>0}+\underbrace{\frac{\partial \pi_{2}}{\partial \rho}(\rho=0)}_{=0}<0 \\
\frac{\partial \Pi(n, A)}{\partial \rho}(\rho=1)=\underbrace{\frac{\partial \pi_{1}}{\partial \rho}(\rho=1)}_{=0}+\underbrace{\frac{\partial \pi_{2}}{\partial \rho}(\rho=1)}_{>0}>0
\end{gathered}
$$

When $\rho=1, \rho\left(p_{A}^{1}-c_{A}^{1}\right)=\frac{\mu_{A}\left(1+\frac{\sigma_{0}^{2}}{\sigma_{1}^{2}}\right)}{\mu_{A}\left(1+\frac{\sigma_{0}^{2}}{\sigma_{1}^{2}}\right)+\Delta \mu} \cdot c_{C}-c_{A}<0$ so there exists some $\bar{\rho}>0$ such that $\pi_{1}(\rho) \equiv 0$, for all $\rho \in(\bar{\rho}, 1]$. Hence by intermediate value theorem, there exists a $\rho^{*} \in(0, \bar{\rho}]$ such that $\frac{\partial \Pi(n, A)}{\partial \rho}\left(\rho=\rho^{*}\right)=0$. 